\title{
A set of cancer stem cell homing peptides associating with the glycan moieties of glycosphingolipids
}

\author{
Yu-Hsiu Su',2, Tai-Yun Lin ${ }^{1}$, Hung-Jen Liu ${ }^{2,3,4}$ and Chin-Kai Chuang ${ }^{1}$ \\ ${ }^{1}$ Division of Biotechnology, Animal Technology Laboratories, Agricultural Technology Research Institute, Hsinchu City 30093, \\ Taiwan \\ ${ }^{2}$ Institute of Molecular Biology, National Chung Hsing University, Taichung City 40227, Taiwan \\ ${ }^{3}$ Rong Hsing Research Center for Translational Medicine, National Chung Hsing University, Taichung City 40227, Taiwan \\ ${ }^{4}$ The iEGG and Animal Biotechnology Center, National Chung Hsing University, Taichung City 40227, Taiwan \\ Correspondence to: Chin-Kai Chuang, email: jkjuang@mail.atri.org.tw \\ Hung-Jen Liu, email: hjliu5257@nchu.edu.tw \\ Keywords: cancer stem cells; homing peptides; glycosphingolipids; Globo H; Lewis Y \\ Received: February 15, $2017 \quad$ Accepted: March 12, $2018 \quad$ Published: April 17, 2018 \\ Copyright: Su et al. This is an open-access article distributed under the terms of the Creative Commons Attribution License 3.0 (CC \\ BY 3.0), which permits unrestricted use, distribution, and reproduction in any medium, provided the original author and source are \\ credited.
}

\section{ABSTRACT}

Cancer stem cells (CSCs) are currently believed to be involved in tumor metastasis and relapse. And treatments against CSCs are well concerned issues. Peptides targeting to mouse and human CSCs were screened from an M13 phage display library. The first subset of cancer stem cell homing peptides (CSC HPs), CSC HP-1 to -12, were screened with mouse EMT6 breast cancer stem cells. Among them, CSC HP-1, CSC HP-3, CSC HP-8, CSC HP-9, and CSC HP-10 can bind to mouse CT26 colon CSCs; CSC HP-1, CSC HP-2, CSC HP-3, and CSC HP-8 can bind to mouse Hepa1-6 liver CSCs; as well as CSC HP-1, CSC HP-2, CSC HP-3, CSC HP-8, CSC HP-9, CSC HP10, and CSC HP-11 can bind to human PANC-1 pancreatic CSCs. The second subset of cancer stem cell homing peptides, CSC HP-hP1 to -hP3, were screened with human PANC-1 pancreatic CSCs. Both CSC HP-hP1 and CSC HP-hP2 were demonstrated able to bind mouse EMT6, CT26 and Hepa1-6 CSCs as well as human colorectal HT29 and lung H1650 CSCs. CSC HP-1 and CSC HP-hP1 could strongly associate with the Globo 4 and Lewis $Y$ glycan epitopes coupled on a microarray chip or Globo 4 and Globo H conjugated on bovine serum albumin. CSC HP-10, CSC HP-11 and CSC HP-hP2 could associate with the disialylated saccharide Neu5Ac-a-2,6-Gal- $\beta-1,3-(N e u 5 A c-$ a-2,6)-GaINAc coupled on a microarray chip. These results indicate that the CSC HPs may target to the known stem cell glycan markers $\mathbf{G b H}$ and Lewis $\mathrm{Y}$ as well as the disialylated saccharide.

\section{INTRODUCTION}

Cancer stem cells (CSCs), also termed as tumor initiating cells (TICs), are operationally defined by their exclusive ability to initiate and maintain tumor growth and are small subpopulations of neoplastic cells within a tumor. Since the $\mathrm{CD} 34^{+} \mathrm{CD} 38^{-}$fraction of human acute myeloid leukemia cells were found can disseminate in the severe combined immune-deficient (SCID) mice [1], TICs were soon identified in breast [2], brain [3], liver [4], colon [5], lung [6], and pancreatic tumors [7]. CSC is quiescent and divides asymmetrically to produce a dormant CSC and a highly proliferative progenitor cell. The asymmetry of CSC division is regulated by NOTCH signaling [8]. And the progenitor cells and their progenies compose the major mass of a tumor $[9,10]$. Because CSCs are relatively quiescent within tumors, they are much less sensitive to anti-cancer drugs acting on highly proliferative cells and participated in tumor propagation after chemotherapies [11]. Additionally, CSCs have a high DNA repairing ability [12] and express high aldehyde dehydrogenase activity [13], ATP-binding cassette (ABC) transporter family proteins [14, 15], as well as anti-apoptosis proteins Bcl2 and Bclxl [for review, see 16-18]. CSCs 
prefer glycolysis rather than oxidative phosphorylation in energy metabolism $[19,20]$ and express a high level of hypoxia induced factor $1 \alpha(\mathrm{HIF} 1 \alpha)$ so as to sustain themselves in a low-oxygen environment [21]. According to these specificities, it is currently believed that CSCs are involved in tumor metastasis and relapse. And therapies aimed at CSCs are deeply concerned issues [22, 23].

CSCs can be enriched from tumor cells using various markers [10]. For example, CD44, $\mathrm{CD} 24$, and $\mathrm{ALDH}^{+}$were selected for breast CSCs $[2,24]$. As few as 100 isolated cells were capable to colonize a tumor in SCID mice [2]. CD44, $\mathrm{CD} 133^{+}, \mathrm{CD} 166^{+}, \mathrm{CD} 24^{+}$, $\mathrm{EpCAM}^{+}, \mathrm{ESA}^{+}$, and $\mathrm{ALDH}^{+}$were set for colon CSCs [25-27]. CD133 ${ }^{+}$and $\mathrm{EpCAM}^{+}$were focused for liver CSCs [28, 29]; as well as CD44 $4^{+}, \mathrm{CD} 133^{+}, \mathrm{CD} 24^{+}, \mathrm{ESA}^{+}$, and $\mathrm{ALDH}^{+}{ }^{+}$were picked for pancreas CSCs $[30,31]$. The expression levels of the CSC markers on the cultured cancer cells are quite dynamic. The population of $\mathrm{CD} 13^{+}$ cells in $\mathrm{Li}-7$ hepatocellular carcinoma line decreased when the passage number increased [32].

Although epithelial-mesenchymal transition (EMT) is a key program mainly involved in cancer invasion and metastasis, it is also involved in generating the properties of stem cells. Ectopic expression of the EMT inducing factors, Twist or Snail, in transformed human mammary epithelial cells induced CD44, CD24- breast CSC phenotype [33]. Overexpression of Snail in human colorectal cancer cell lines, HT29 and HCT116 also increased the expression of CD44 and CD133 antigens [34]. Such kinds of cells cultured in two-dimensional (2-D) state cannot mimic CSCs precisely. Three-dimensional (3-D) cultures were developed to selectively expand normal and cancer mammary stem cells [35]. When the trypsinized single cell suspensions were cultured in serum-free media in ultra-low attachment plates at low density, the differentiated cells died because of anoikis $[36,37]$ and only stem cells could survive. Each stem cell could proliferate to a clump of cells named as mammosphere. As few as 500 cells of mammospheres could colonize a tumor on SCID mouse, therefore, the mammospheric cells were generally recognized as breast CSCs [35, 38, 39]. Serum-free 3-D cultures of other cancers, such as melanoma [40], brain tumor [3, 41], colon cancer [42], liver cancer [28], and pancreatic cancer [43] were also established and the cells composing of these cell clumps are termed as CSCs. Weiswald et al. suggested to nomenclature these cancer cell clumps prepare in serum-free media in non-attachment plates as tumorospheres in order to distinguish between multicellular tumor spheroids (MTSs) which were prepared in the presence of serum [44]. Under the last condition, the tumor cells of different types and differentiated states in a single cell suspension will aggregate to form organized and compact cell clumps [45, 46].

Although antibodies are currently used for cancer targeting, the tumor homing peptides (THPs) are superior in some aspects because of their small sizes. THPs are less immunogenic, deeper tumor penetrating and can be synthesized multi-valently and economically. Phage displayed random peptide libraries have been used and two general strategies are applied to screen THPs. In the first strategy, target proteins coated on the bottom of ELISA plates or cancer cells on culture plates were treated with phage libraries which were either pre-absorbed with nonspecific proteins or normal cells. The phages absorbed on the targets were stripped and then amplified in host bacteria to get round-one enriched library. The panning procedures are usually repeated for three to seven rounds. By this strategy, the THPs specifically binding to either tumor antigens, such as HER2 [47] and CD21 [48], or to cancer cells, such as glioma [49], hepatoma [50], nasopharengeal carcinoma [51], and lung cancer cells [52-54], were reported. On the other hand, in vivo biopanning strategy was taken. Phage libraries were injected from the tail vein of a SCID mouse xenotransplanted with tumors. The phages entrapped inside the tumors were eluted and amplified as described above. The neoplastic vasculature is distinct from the normal one on the basis of structure and gene expression $[55,56]$. It can be conceived that the majority of the THPs screened by the in vivo biopanning were verified associating with the endothelial cells of the neoplastic vasculatures. These THPs can be categorized as (i) peptides with RGD motif targeting to integrin $\alpha_{v} \beta_{3}$ and $\alpha_{v} \beta_{5}$ on the endothelia of the neoplastic blood vasculatures [57, 58], (ii) peptides with NGR motif targeting to CD13/aminopeptidase $\mathrm{N}$ on the endothelia of the neoplastic blood vasculatures [59, 60], and (iii) peptides targeting to neoplastic lymphatic vessels [61-63]. The THP sequence database, TumorHoPe, systematically collected from the published papers, patents and websites was released on-line [64].

In this report, CSCs prepared by the 3-D tumorosphere with serum-free culture methods from mouse breast, colon, and liver cancer cell lines as well as human pancreatic cancer cell line were used to screen peptides which prefer binding to CSCs than cancer cells (CCs). A subset of cancer stem cell homing peptides (CSC HPs) was selected from a phage displayed random peptide library by mouse breast CSCs. These CSC HPs can recognize mouse colon and liver CSCs as well as human pancreatic CSCs, even with various tendencies. Another subset of CSC HPs screened by human pancreatic CSCs was collected too. They can recognize mouse CSCs vice a versa. The targets of these CSC HPs have been explored and some possible candidates are reported hereafter.

\section{RESULTS}

\section{Surface markers of CSCs}

Although CD44 and CD133 have been used to enrich CSCs from human breast cancer [2, 24], colon cancer [25-27], and liver cancer [28, 29], CD44 was detected on the mouse breast EMT6, colon CT26, and liver Hepa1-6 CCs. CD133 is also monitored on EMT6 CCs (Figure 1B). Another set of CSC surface markers were needed to distinguish these CSCs from CCs. Since 
A EMT6

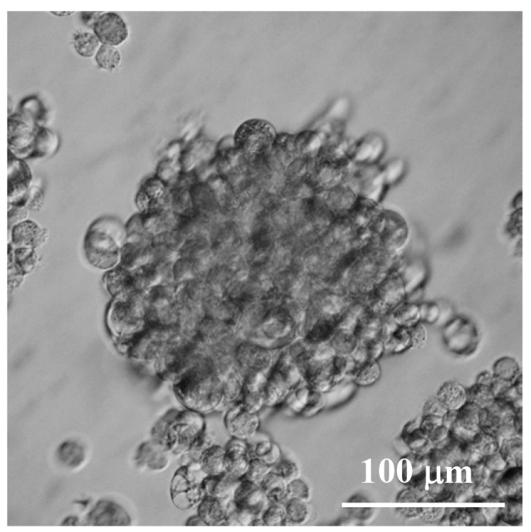

CT26

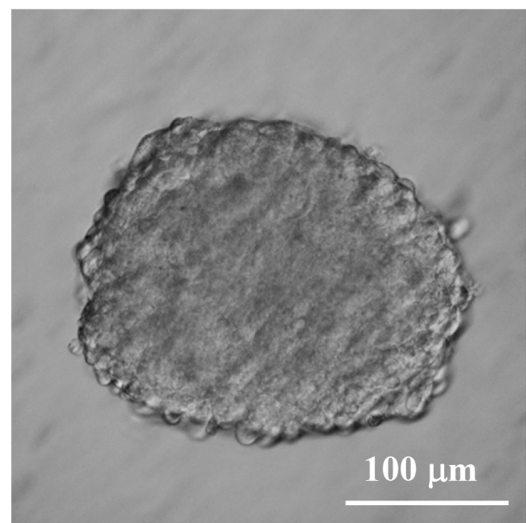

\section{Hepa1-6}

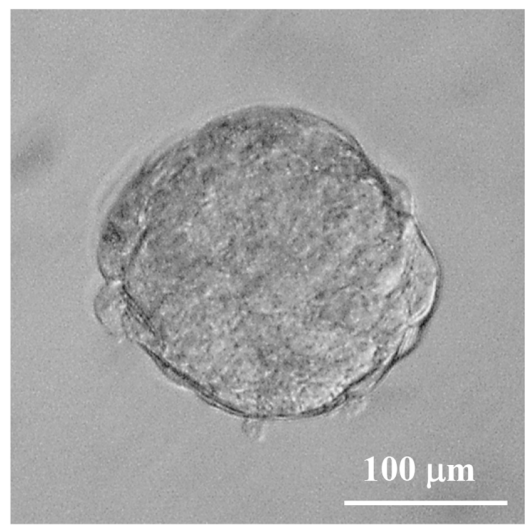

B
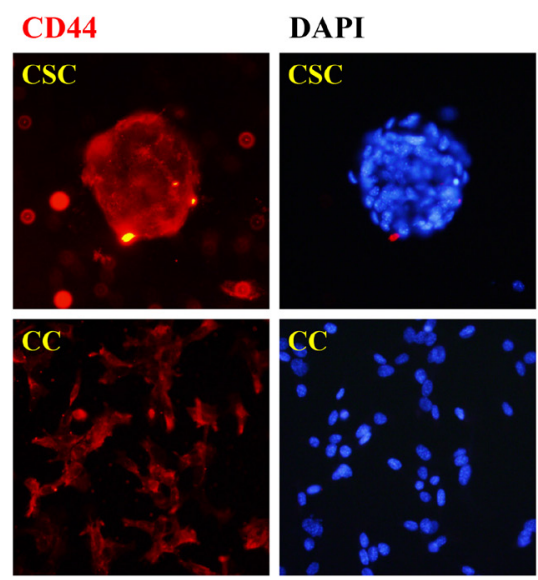

Merge
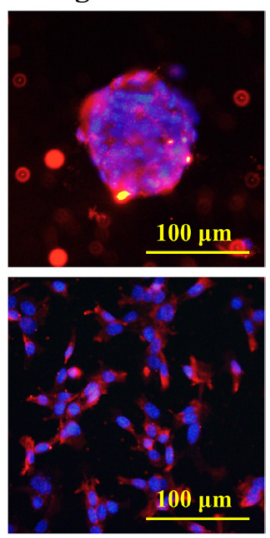

Globo H

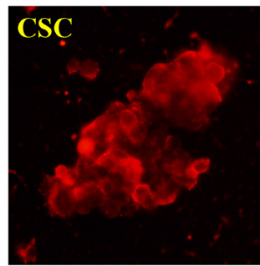

DAPI

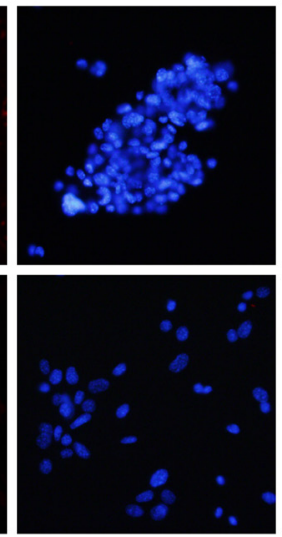

Merge

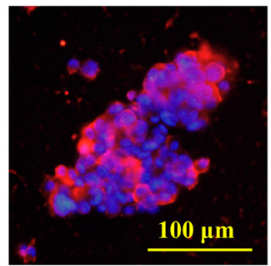

CC
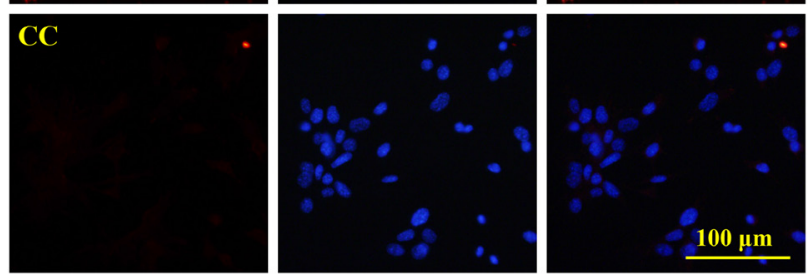

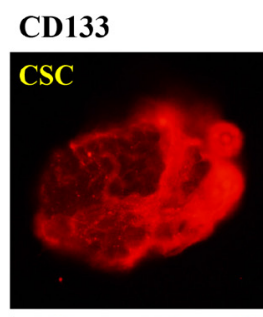

DAPI

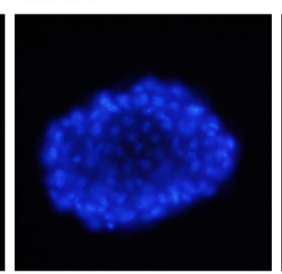

Merge
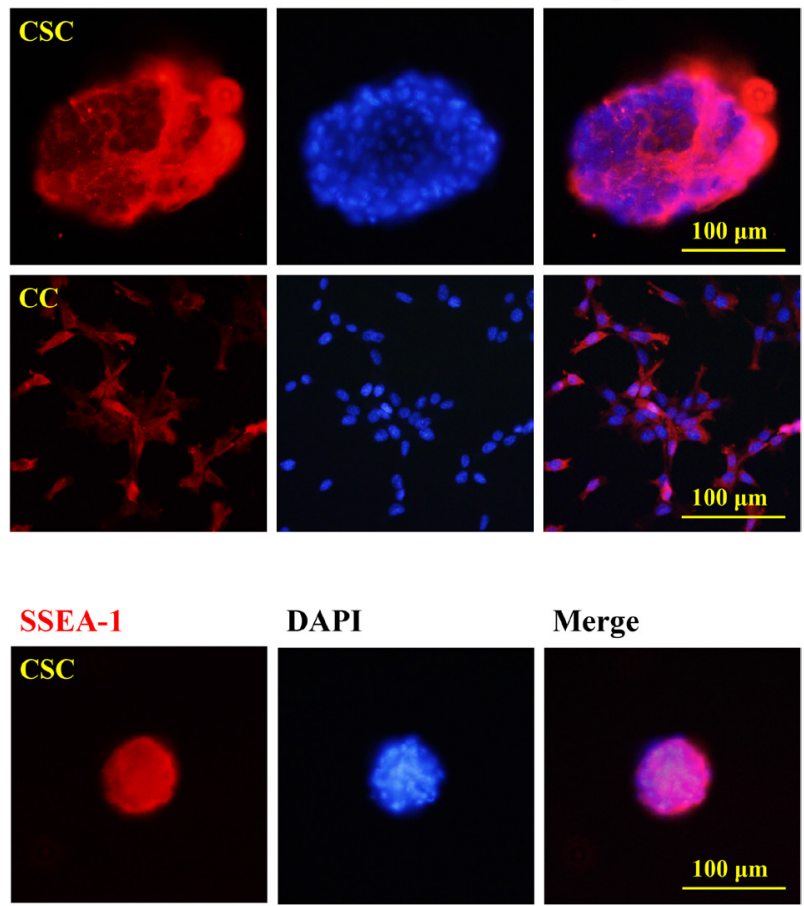

DAPI

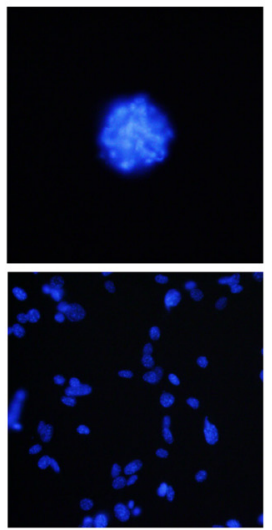

Merge

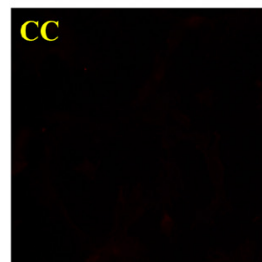

Figure 1: Preparation and characterization of mouse CSCs. (A) Tumorospheres of mouse EMT6 breast cancer cells (left panel), CT26 colon cancer cells (middle panel), and Hepa1-6 liver cancer cells were prepared. (B) EMT6 CSCs and CCs were incubated with primary antibodies against CD44, CD133, Globo H (GbH), and SSEA-1 epitopes on EMT6 CSCs and CCs. Either DyLight594-conjugated goat anti-Rabbit IgG for CD44 and CD133 or DyLight594-conjugated goat anti-mouse IgM for Globo H and SSEA-1 were used as secondary antibodies.

(Continued) 
C

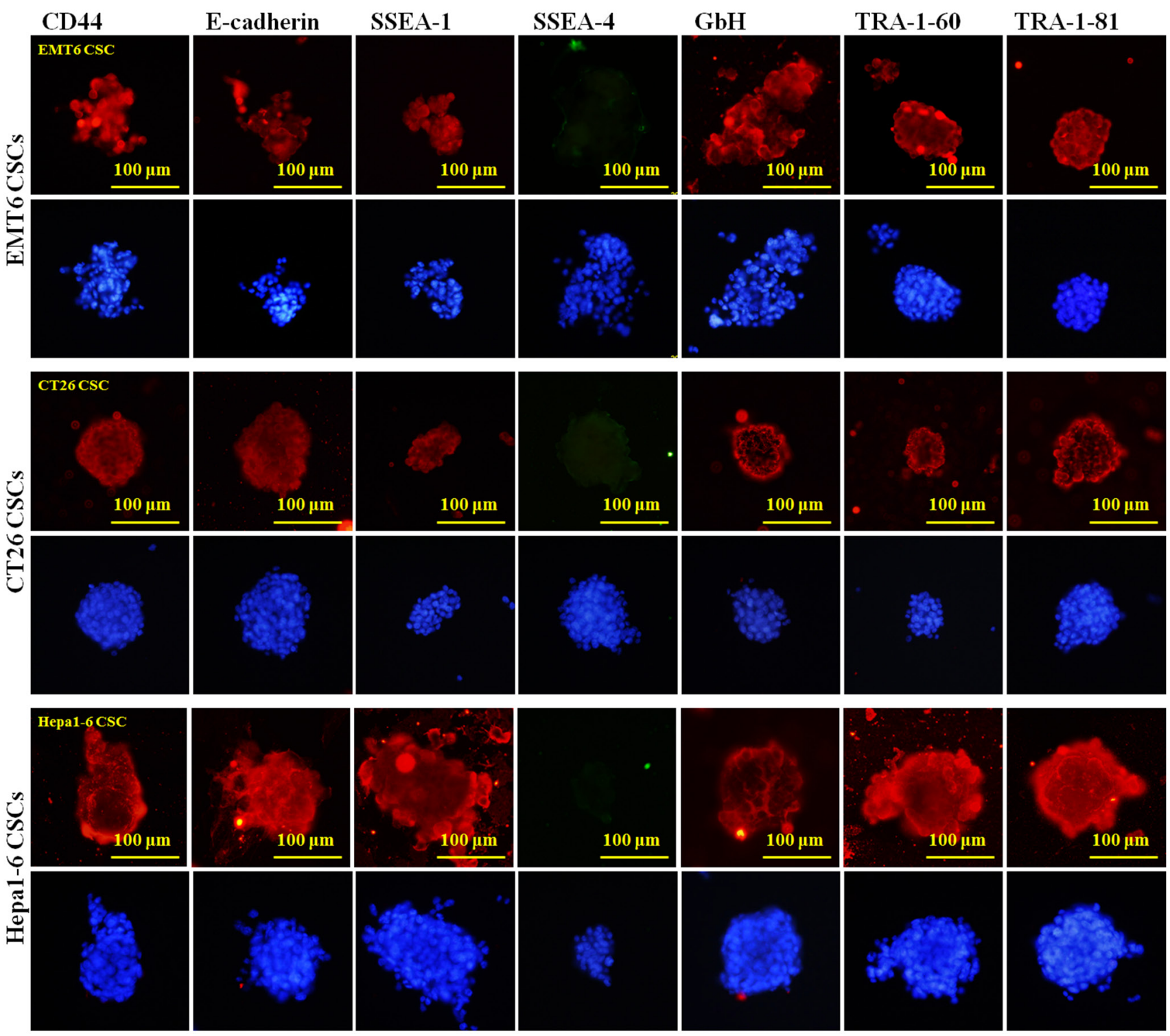

Figure 1 (Continued): (C) The IF images of EMT6, CT26 and Hepa1-6 CSCs were performed with primary antibodies against CD44, E-cadherin, SSEA-1, SSEA-4, GbH, TRA-1-60, and TRA-1-81 antibodies followed with secondary antibodies DyLight594-conjugated goat anti-Rabbit IgG for CD44 and E-cadherin, DyLight594-conjugated goat anti-mouse IgM for SSEA-1, GbH, TRA-1-60, and TRA-181, as well as DyLight488-conjugated donkey anti-mouse IgG for SSEA-4. The scaling bars of $100 \mu \mathrm{m}$ are shown.

stage-specific embryonic antigen-3 (SSEA-3) has been reported specific for human breast CSCs [65], a series of antibodies against early embryonic developmental markers $[66,67]$ were tested. Like human cancer cell lines, mouse CSCs can be prepared as tumorospheres by the serumfree culture methods (Figure 1A). Besides SSEA-1 and $\mathrm{GbH}$ which were detected on EMT6 CSCs rather than CCs (Figure 1B), the embryonic stem cell (ESC) markers, SSEA-1, GbH, TRA-1-60 and TRA-1-81, as well as epithelial marker E-cadherin were just detected on the CSCs of EMT6, CT26 and Hepa-1 (Figure 1C) but not on the CCs. Like mouse ESCs, SSEA-4 was not detected on mouse CSCs.

\section{Screening of CSC specific HPs from a phage display library}

The flow chart of strategy to explore mouse CSC specific HPs is shown in Figure 2A. The M13 PhD7 hepta-peptide library was pre-adsorbed by EMT6 CCs to remove the general cancer HPs, then the free phages were transferred to EMT6 CSCs for positive selection. The phages associated on EMT6 CSCs were trapped and amplified by E. coli ER2738. The aforementioned selection procedures were carried out for three rounds to prepare an enriched primary EMT6 CSC HP library. Independent plaques were randomly picked and 31 valid 
sequences were read and summarized in Table 1. Peptide SQPTWMF (signed as CSC HP-1), GMMSSPP (CSC HP-2), FSGGGNH (CSC HP-3), FPFTKNL (CSC HP4), and ATYGNLW (CSC HP-5) occurred 10, 6, 5, 3, and 2 times, respectively. The other peptides, YHMPALM (CSC HP-6), HGGVRLY (CSC HP-7), ELTPLTL (CSC HP-8), GPSASRN (CSC HP-10), and GLAPFNA (CSC HP-11) appeared once. Since the M13 PhD7 library was estimated to contain $10^{9}$ independent clones, it can be concluded that the selection procedures were highly effective.

The primary CSC HP-library was further selected directly once by either CT26 or Hepa1-6 CSCs to test the bias of CSC HP affinities to different kinds of cancers. As the data show in Table 1, CSC HP-8 and CSC HP-3 were more attractive for CT26 and Hepa1-6 CSCs,

A
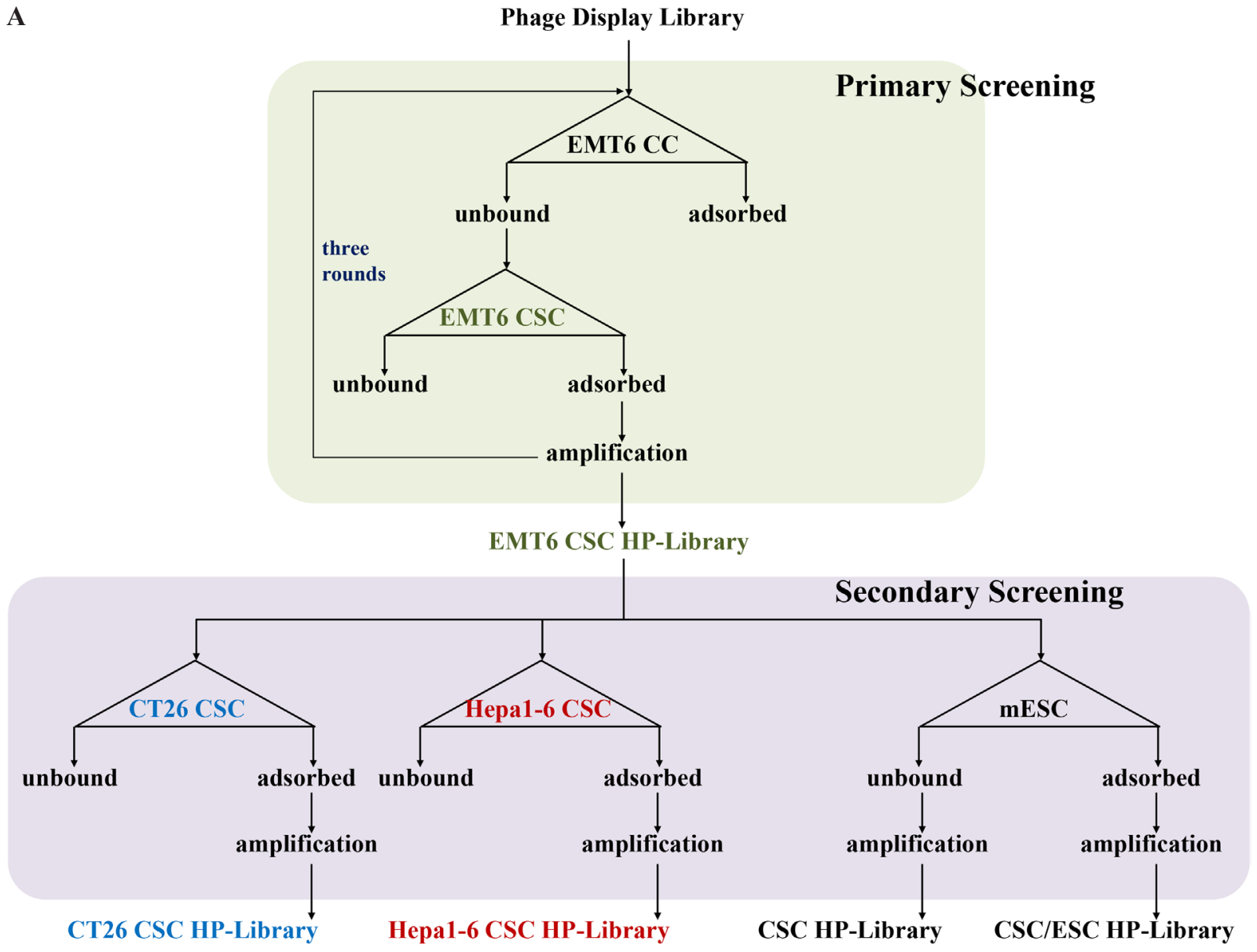

B

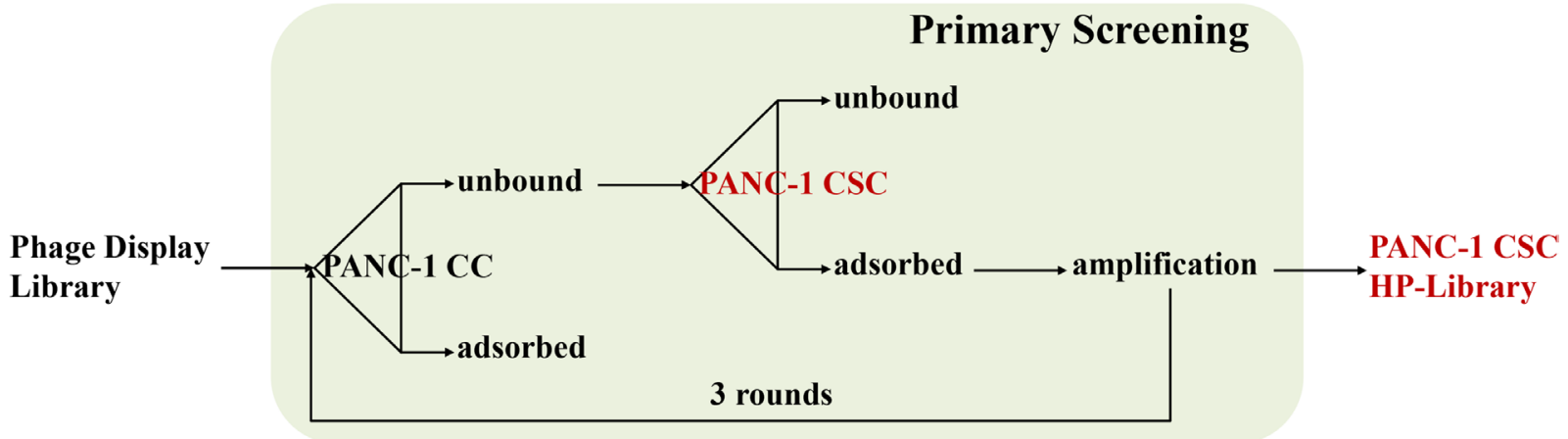

Figure 2: Strategies for the establishment of primary and secondary CSC HP libraries. (A) Flow chart of the primary screening from the original M13 PhD7 library to prepare the EMT6 CSC HP-Library was shown in the upper part. The secondary screening tactics to produce the CT26 CSC HP-Library, the Hepa1-6 CSC HP-Library, the CSC/ESC HP-Library, and the CSC HP-Library was illustrated in the lower part. (B) The same strategy of EMT6 CSC HP-library preparation was used to establish the PANC-1 CSC HP-library. 
Table 1: The times of CSC HP sequences detected in the primary and secondary CSC HP-libraries

\begin{tabular}{|c|c|c|c|c|c|c|}
\hline \multicolumn{2}{|c|}{ CSC HP } & \multirow{2}{*}{$\frac{\text { Primary }}{\text { EMT6 }(n=31)}$} & \multicolumn{4}{|c|}{ Secondary } \\
\hline Name & Sequence & & CT26 $(n=20)$ & Hepa1-6 $(n=10)$ & $\operatorname{CSC} / \operatorname{ESC}(n=20)$ & $\operatorname{CSC}(n=20)$ \\
\hline CSCHP-1 & SQPTWMF & 10 & 6 & 0 & 11 & 8 \\
\hline CSCHP-2 & GMMSSPP & 6 & 3 & 0 & 1 & 1 \\
\hline CSCHP-3 & FSGGGNH & 5 & 1 & 10 & 1 & 1 \\
\hline CSCHP-4 & FPFTKNL & 3 & 0 & 0 & 2 & 2 \\
\hline CSCHP-5 & ATYGNLW & 2 & 1 & 0 & 1 & 2 \\
\hline CSCHP-6 & YHMPALM & 1 & 1 & 0 & 1 & 2 \\
\hline CSCHP-7 & HGGVRLY & 1 & 1 & 0 & 1 & 2 \\
\hline CSCHP-8 & ELTPLTL & 1 & 7 & 0 & 2 & 0 \\
\hline CSCHP-9 & KIYTTLD & 0 & 0 & 0 & 0 & 1 \\
\hline CSCHP-10 & GPSASRN & 1 & 0 & 0 & 0 & 0 \\
\hline CSCHP-11 & GLAPFNA & 1 & 0 & 0 & 0 & 0 \\
\hline CSCHP-12 & NLQPPAY & 0 & 0 & 0 & 0 & 1 \\
\hline
\end{tabular}

respectively. The bias of CSC HP affinities between CSCs and embryonic stem cells (ESCs) was another interesting issue. The CSC HP-1 was further enriched in the ESC bound fraction (CSC/ESC-HP-library). Two new peptide sequences, KIYTTLD (CSC HP-9) and NLQPPAY (CSC HP-12), were read in the ESC unbound fraction (CSC HPlibrary) (Table 1).

\section{Interactions between CSC HPs and CSCs}

According to these results, CSC HP-1, CSC HP2, CSC HP-3, CSC HP-8, CSC HP-9, CSC HP-10, and CSC HP-11 were selected and chemically synthesized with $\mathrm{N}$-terminal conjugation with rhodamine B (Rd-CSC HPs) or fluorescein (FITC-CSC HPs) as listed in Table 2. All of these peptides specifically associated with EMT6, CT26 and Hepa1-6 CSCs. They were not detectable in the parallel CC experiments (Figure 3A and 3B). It was of interest to determine whether these CSC HPs derived from mouse cancers could recognize human CSCs. Tumorospheres prepared from the human pancreatic cancer cell line PANC-1 were found to be associated with the seven peptides. (Figure 3B)

\section{Primary PANC-1 CSC HP Library}

If the CSC HPs selected by mouse CSCs could cross-react with human CSCs, could the CSC HPs selected by human CSCs associate with mouse CSCs? Following the similar procedures of EMT6 CSC HP screening, after three rounds of negative selection with human pancreatic PANC-1 CCs and positive selection with PANC-1 CSCs, a primary PANC-1 CSC HP-library was established. Independent plaques were randomly picked and 20 valid sequences were read. Peptide GPKVTIW (as signed as CSC HP-hP1), GSPVMSW (CSC HP-hP2), and YHQVKPH (CSC HP-hP3) occurred 17, 2, and 1 times, respectively. (Table 3 ) The amino acid sequences of the CSC HP-hP series did not match those of the mouse CSC HPs. In addition to chemically synthesized Rd-CSC HP-hP1, which could selectively associate with human PANC-1CSCs (Figure 4A). Besides PANC-1 CSCs, RdCSC HP-hP1 and Rd-CSC HP-hP2 could also associate with human colorectal cancer HT29 and lung cancer H1650 CSCs as well as mouse EMT6, CT26 and Hepa1CSCs (Figure 4C), CSC HP-hP1-DsRed recombinant protein was prepared to test whether the interactions between CSC HP-hP1 and CSCs would be affected by a large molecule cargo fused to the C-terminus of CSC HP-hP1 peptide. The CSC HP-hP1-DsRed recombinant protein was demonstrated able to bind to all of the six kinds of CSCs tested (Figure 4B and 4C).

\section{Targets of the CSC HPs}

The CSC HPs isolated could distinguish CSCs from CCs, and this phenomenon was found cross-species between human and mouse. It was very interesting to figure out the targets of these CSC HPs. There were no detectable fluorescent signals of FITC-CSC HPs remaining on the nitrocellulose membrane that had been blotted with CSC membrane proteins separated by SDS PAGE (data not shown). Glycan microarray (Glycan Array 100 microchips), on which 100 kinds of oligosaccharides were spotted 4 times, was utilized to analyze the possibilities of the interactions between oligosaccharides and CSC HPs. 
Table 2: Chemically synthesized Rhodamine-, Fluorescein- and Biotin-conjugated CSC HPs

\begin{tabular}{lccc}
\hline Conjugation & Rhodamine B & Fluorescein & Biotin \\
\hline CSC HP-1 & Rd-GSQPTWMF & Biotin-GGSQPTWMF \\
CSC HP-2 & Rd-GMMSSPP & Biotin-GGMMSSPP \\
CSC HP-3 & & Biotin-GGFSGGGNH \\
CSC HP-4 & & Biotin-GGFPFTKNL \\
CSC HP-5 & & Biotin-GGATYGNLW \\
CSC HP-6 & & Biotin-GGYHMPALM \\
CSC HP-7 & & Biotin-GGHGGVRLY \\
CSC HP-8 & & Biotin-GGELTPLTL \\
CSC HP-9 & & Biotin-GGKIYTTLD \\
CSC HP-10 & FITC-GELTPLTL & Biotin-GGPSASRN \\
CSC HP-11 & FITC-GKIYTTLD & Biotin-GGLAPFNA \\
CSC HP-12 & FITC-GPSASRN & Biotin-GGNLQPPAY \\
CSC HP-hP1 & FITC-GLAPFNA & Biotin-GGPKVTIW \\
CSC HP-hP2 & & Biotin-GGSPVMSW \\
CSC HP-hP3 & & & Biotin-GGYHQVKPH \\
\hline
\end{tabular}

Biotin-CSC HPs as listed in Table 2 were incubated with glycans on the chips. The biotin-CSC HPs trapped on the chips were explored with Cy3-conjugated streptavidin, and the fluorescent signals on them were read by a laser scanner. Two major patterns were illustrated in Figure 5. The first one included glycan 16 (Gal- $\beta-1,4-G 1 c-\beta-), 18$ (Gal- $\alpha-1,4-G a l-\beta-1,4-G l c-\beta-$, also called as Gb3), and 26 (GalNAc- $\beta-1,3-$ Gal- $\alpha-1,4-$ Gal- $\beta-1,4-G l c-\beta-$, also called as Gb4) Globo series (Figure 5A). Typical cases were CSC HP-1 and CHC HP-hP1 (Figure 5C). In addition to the Globo series signals, the second major pattern involved the glycan 19 (GlcNAc- $\beta-1,3-$ Gal- $\beta$-1,4-Glc- $\beta$-, the Lacto tri-saccharide Lc3), which was similar to the level of signal 26 (Figure 5B). The typical cases were CSC HP5, CSC HP6, CSC HP7, and CSC HP9 (Figure 5C). Another two glycan markers, signal 63 (Fuc- $\alpha-1,2-$ Gal- $\beta-1,4-($ Fuc$\alpha-1,3)-G l c N A c-\beta$-, also called Lewis $\mathrm{Y}\left(\mathrm{Le}^{\mathrm{Y}}\right)$ epitope $)$ and signal 69 (Neu5Ac- $\alpha-2,6-G a l-\beta-1,3-($ Neu5Ac- $\alpha-2,6)-$ GalNAc- $\beta-$, , were also detected. CSC HP-1 and CSC $\mathrm{HP}-\mathrm{hP} 1$ performed higher signals on glycan 63 , and CSC HP-9, CSC HP-10, CSC HP-11, CSC HP-hP2, and CSC HP-hP3 performed higher signals on glycan 69 (Figure $5 \mathrm{D})$. According to these results, the stem cell markers of the Globo series, SSEA-4 and GbH, of the Lacto series, SSEA-5 and of the Neolacto series, SSEA-1 and Le ${ }^{\mathrm{Y}}$, on the CSCs of human PANC-1 and HT29 as well as mouse CT26 were analyzed by IF assays. Except SSEA-4 was not found on CT26 CSCs, all of the five glycan antigens were detected on these CSCs (Figure 5E).
The dependence on the geometry of the two sialic acid linked to the terminal Gal- $\beta-1,3-G a l N A c-$ glycan was studied by analyzing the relative signal intensities of glycan 66 (Gal- $\beta-1,3-G a l N A c-\beta-)$, glycan 67 (Gal- $\beta$ $1,3-(N e u 5 A c-\alpha-2,6)-G a l N A c-\beta-)$, glycan 68 (Neu5Ac$\alpha-2,6-$ Gal- $\beta-1,3-$ GalNAc- $\beta$-), glycan 69 (Neu5Ac- $\alpha-2,6-$ Gal- $\beta-1,3-(N e u 5 A c-\alpha-2,6)-G a l N A c-\beta-)$, and glycan 70 (Neu5Ac- $\alpha-2,3-$ Gal- $\beta-1,3-(N e u 5 A c-\alpha-2,6)$-GalNAc- $\beta-$ )

(Supplementary Figure 3). Both of the two Neu5Ac- $\alpha-2,6-$ linkages are necessary for the associations with the CSC HPs (Figure 6A). The enzymes, ST6GalNAc5 and ST6Gal1, involved in the formation of these two likages were analyzed by western blotting method. Both of the two proteins were selectively expressed in PANC-1 CSCs (Figure 6B).

\section{The interactions between CSC HPs and Gb4 and GbH}

The longest globo series glycan spotted on the Glycan Array 100 is Gb4, however, Gb4 is an intermediate during the stem cell antigens SSEA-4 and GbH synthesis pathway (Supplementary Figure 2). The interactions between CSC HPs and Gb4 or GbH were monitored by the free form of rhodamine conjugated CSC HPs in the presence of either $\mathrm{Gb} 4$ or $\mathrm{GbH}$ chemically coupled to BSA (Gb4-BSA and GbH-BSA, respectively). As data shown in Figure 7, Rd-CSC HP-1, Rd-CSC HP-9, Rd-CSC HPhP1, and Rd-CSC HP-hP2 were trapped by Gb4-BSA and $\mathrm{GbH}-\mathrm{BSA}$, but not by BSA alone. Weaker associations 

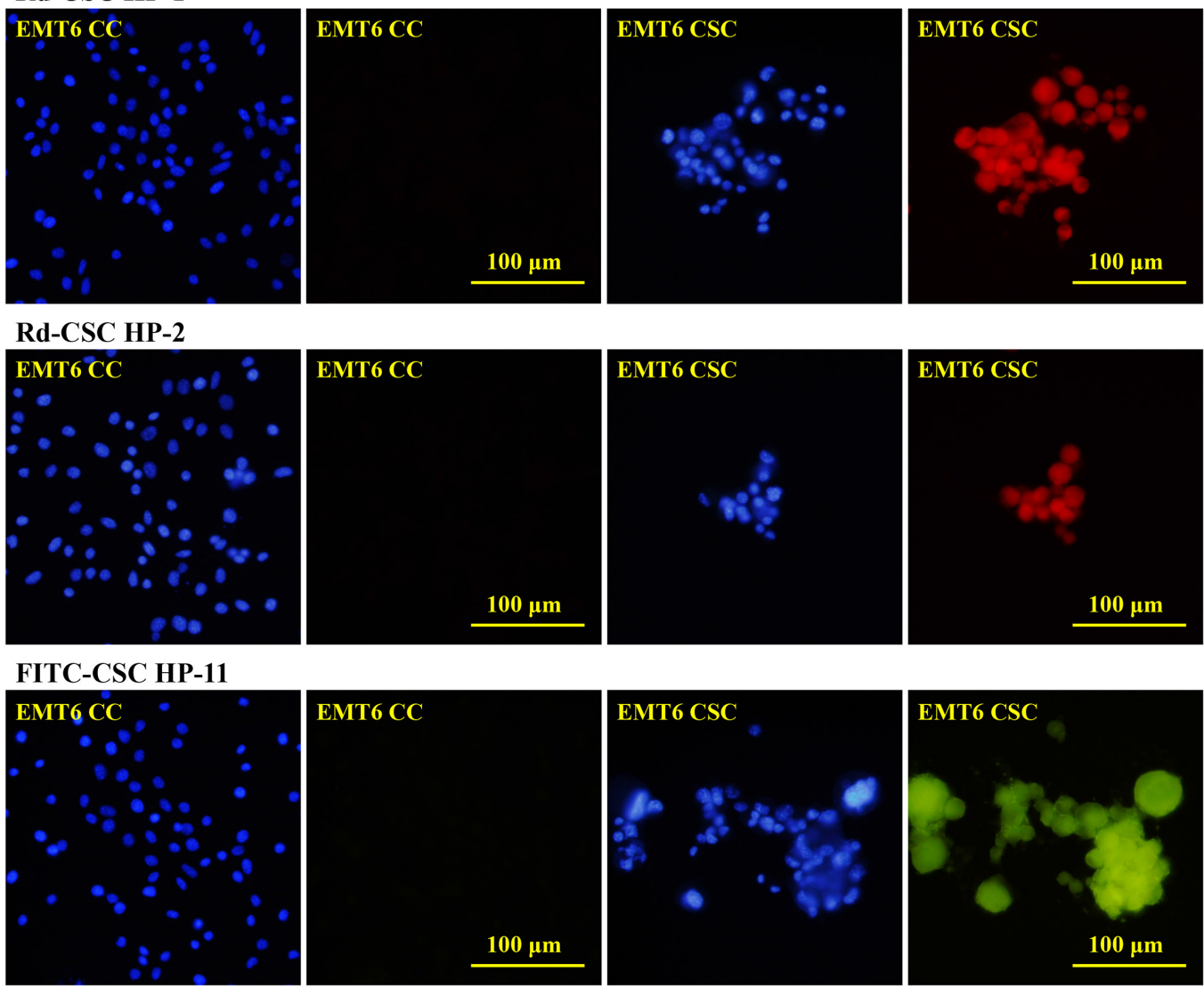

B
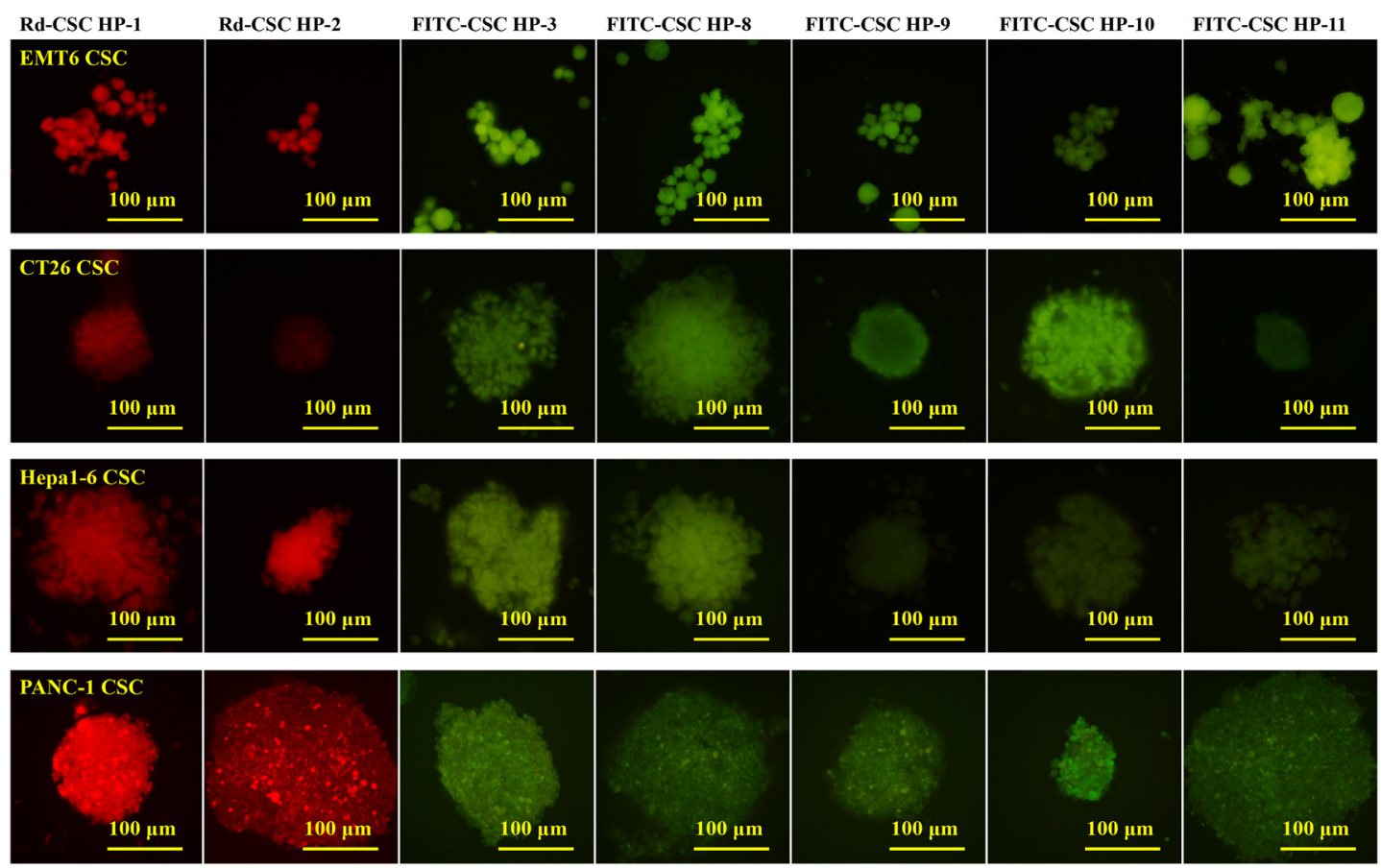

Figure 3: Selective binding of CSC HPs to CSCs. (A) Rhodamine B labeled CSC HP1 (Rd-CSC HP-1) and CSC HP2 (Rd-CSC HP-2) as well as FITC labeled CSC HP11 (FITC-CSC HP-11) were directly used to stain EMT6 CSCs and CCs. Cells were counter-stained with DAPI. (B) The CSCs of EMT-6, CT26, Hepa1-6 and PANC-1 were separately stained with Rd-CSC HP-1, Rd-CSC HP-2, FITC-CSC HP-3, FITC-CSC HP-8, FITC-CSC HP-9, FITC-CSC HP-10 or FITC-CSC HP-11. Fluorescence images were captured with the same exposure conditions. Either $50 \mu \mathrm{g} / \mathrm{mL}$ of Rd-CSC HPs or FITC-CSC HPs were used to stain these CSCs. All the pictures were of the same magnification and taken with $40 \times$ objective lens. The scaling bars of $100 \mu \mathrm{m}$ are shown on the right panel pictures. 
Table 3: The times of CSC HP sequences detected in the primary PANC-1CSC HP-libraries

\begin{tabular}{llc}
\hline & CSC HP & Primary \\
\hline Name & Sequence & PANC-1 (n=20) \\
\hline CSC HP-hP1 & GPKVTIW & 17 \\
CSC HP-hP2 & GSPVMSW & 2 \\
CSC HP-hP3 & YHQVKPH & 1 \\
\hline
\end{tabular}

A

\section{Rd-CSC HP-hP1}

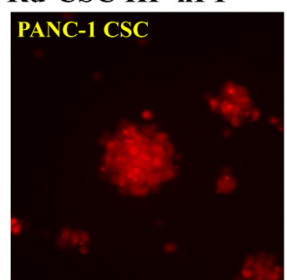

PANC-1 CC
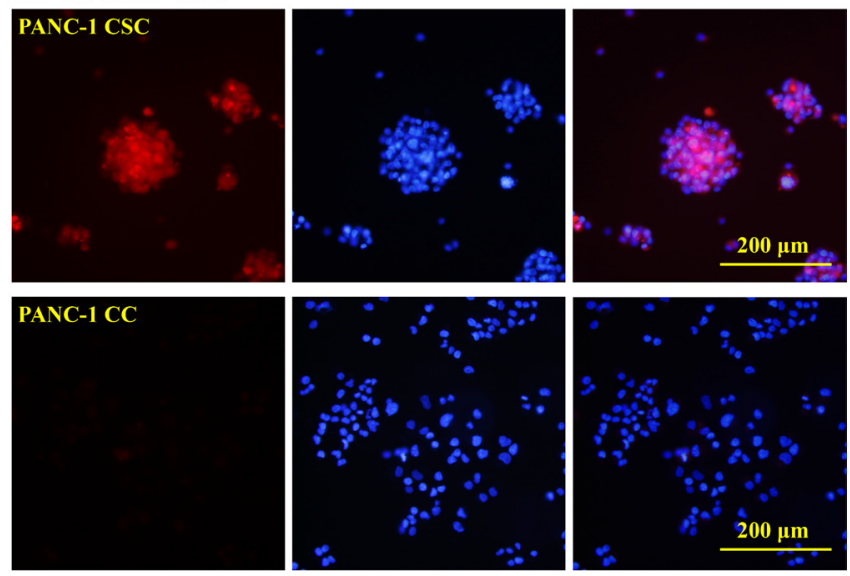

C
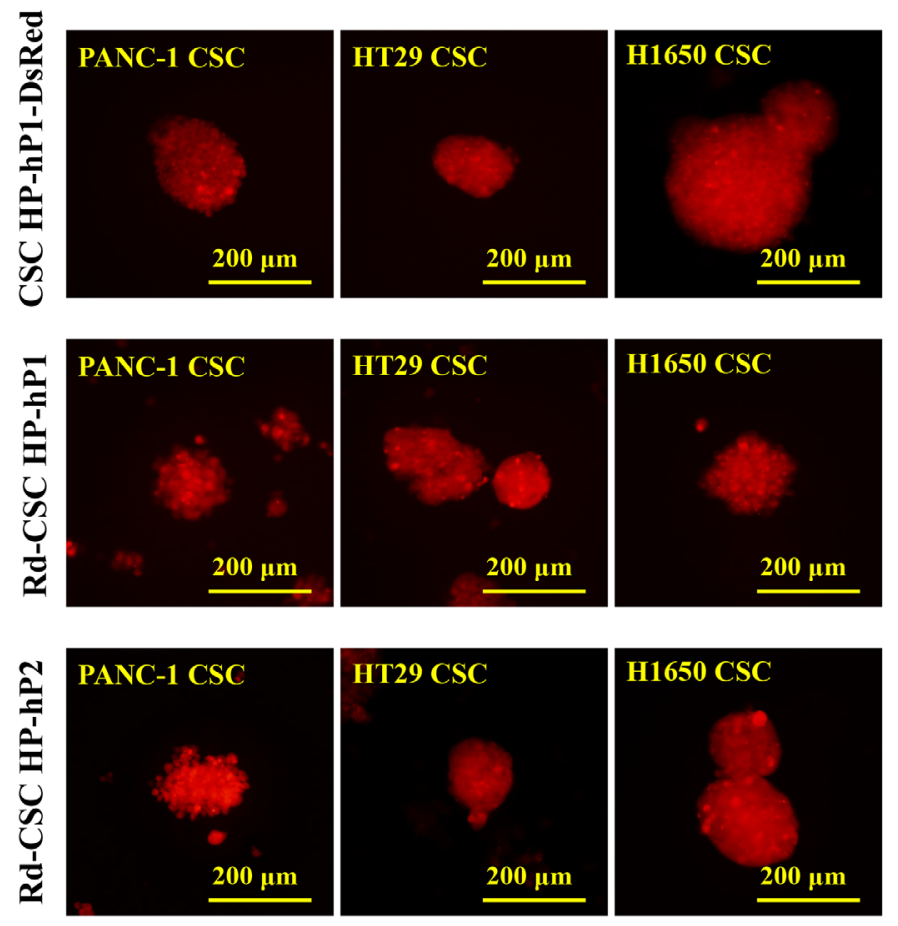

B

\section{CSC HP-hP1-DsRed}
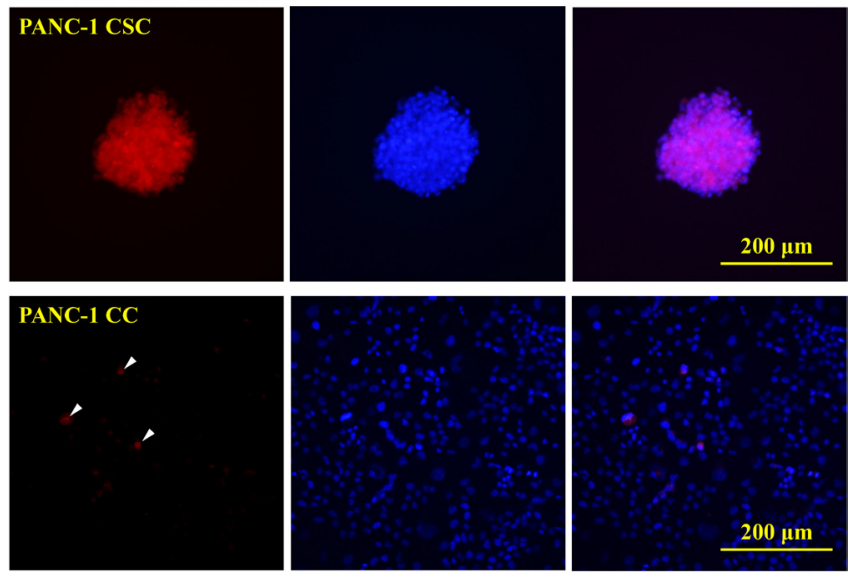
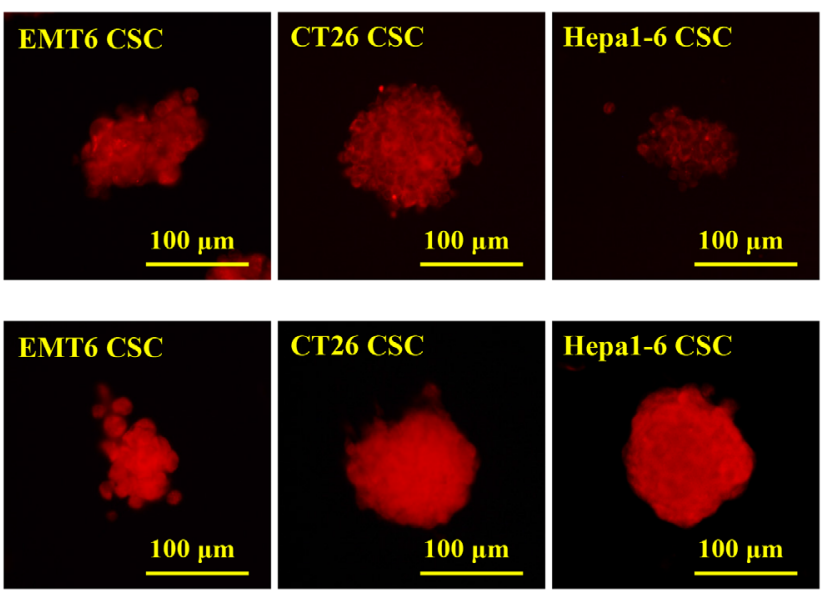

Figure 4: Selective binding of CSC HP-hPs to CSCs. (A) PANC-1 CSCs and CCs were stained with $50 \mu \mathrm{g} / \mathrm{mL}$ of Rd-CSC HP-hP1. (B) PANC-1 CSCs and CCs were stained with $25 \mu \mathrm{g} / \mathrm{mL}$ of CSC HP-hP1-DsRed recombinant protein. Some PANC-1 CCs stained were indicated by arrowheads. (C) The CSCs of human PANC-1, HT29 and H1650 as well as mouse EMT6, CT26 and Hepa-1 were stained with $25 \mu \mathrm{g} / \mathrm{mL}$ of CSC HP-hP1-DsRed recombinant protein (upper panels, $50 \mu \mathrm{g} / \mathrm{mL}$ of Rd-CSC HP-hP1 (middle panels), or $50 \mu \mathrm{g} / \mathrm{mL}$ of Rd-CSC HP-hP2 (lower panels). The pictures of human and mouse CSCs were taken with $20 \times$ and $40 \times$ objective lens, respectively. The scaling bars of $200 \mu \mathrm{m}$ for human CSCs or $100 \mu \mathrm{m}$ for mouse CSCs are presented. 
A

Biotin-CSC HP-hP1 $(1 \mu \mathrm{g} / 400 \mu \mathrm{L})$

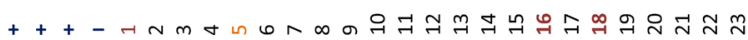

సั่

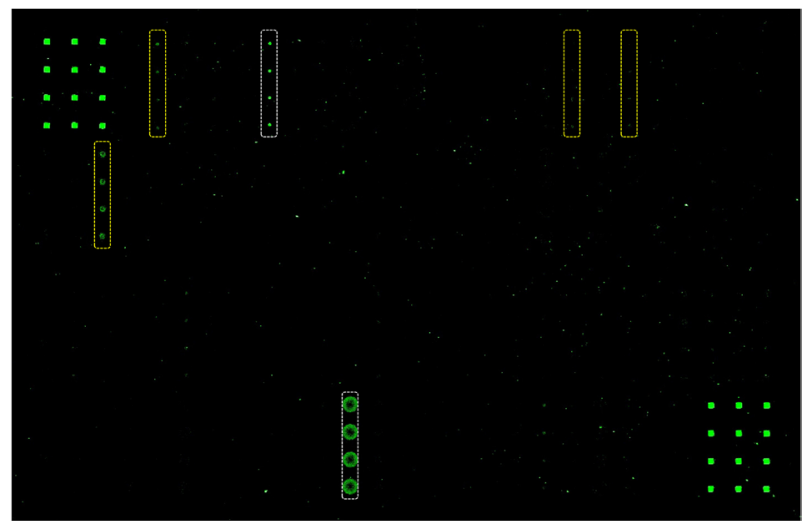

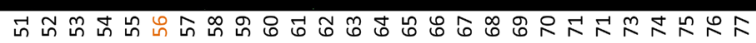

வ இ

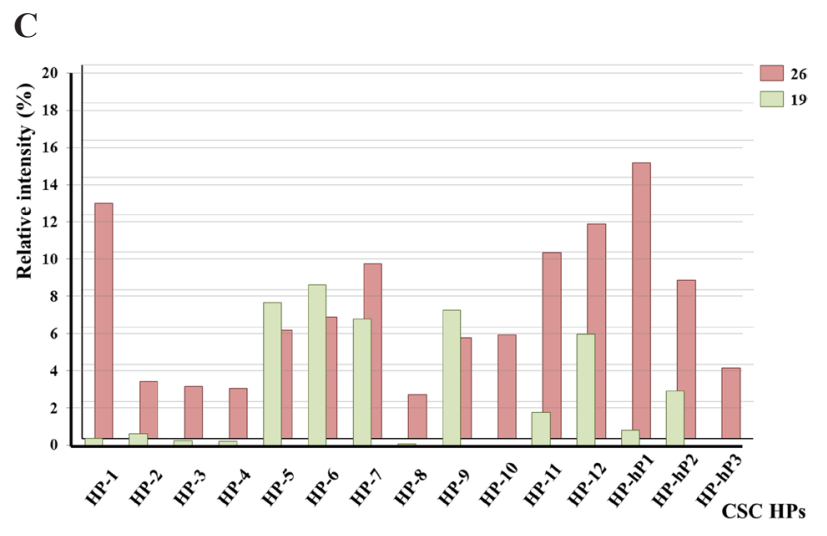

B

Biotin-CSC HP-9 $(1 \mu \mathrm{g} / 400 \mu \mathrm{L})$

ఈn

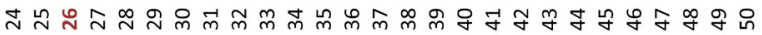

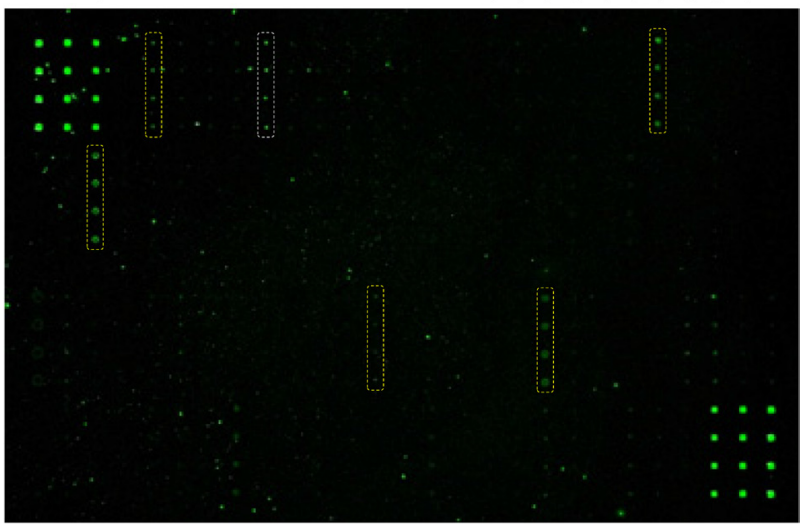

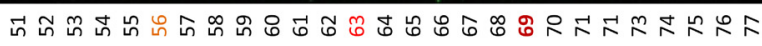

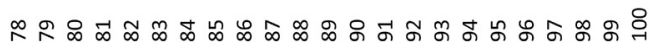

D

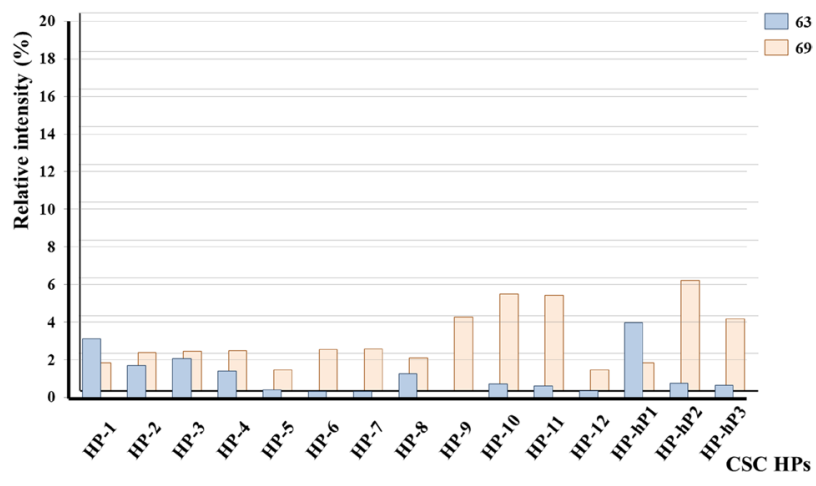

$\mathbf{E}$

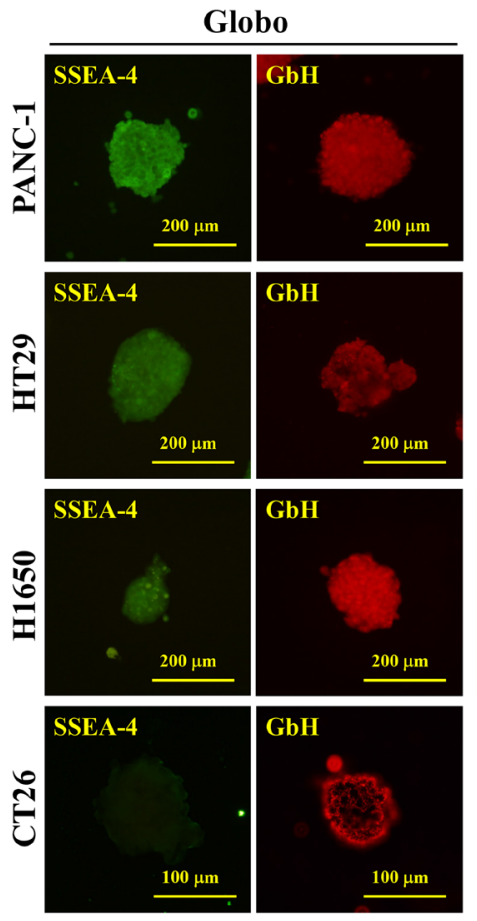

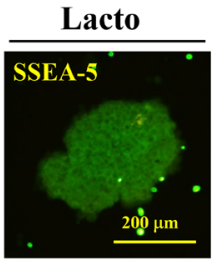
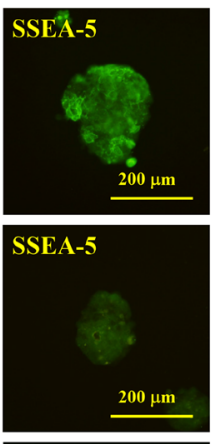

SSEA-5

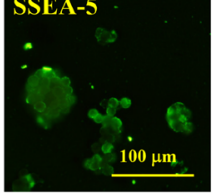

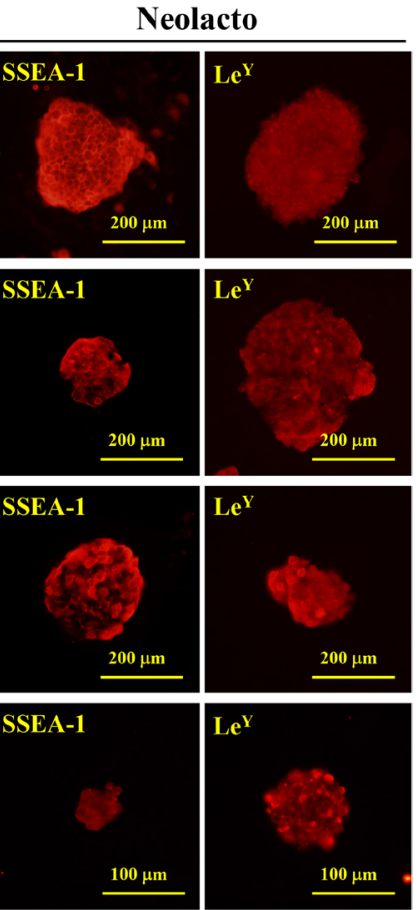

(Continued) 
Figure 5 (Continued): Targets of CSC HPs analyzed by glycan microarray. Glycan microarray analysis of CSC HP-hP1 (A) and CSC HP-9 (B) labeled with biotin was performed. The tetra-plicate spots of interest were marked with a yellow dash line. Strong signals, such as glycan 5 ( $\alpha$-Rha) and glycan 89 ( $\beta$-1,4-Xylotetraose), without apparent significance were marked with a white dash line. (C) The average relative intensities of Globo (glycan 26) versus Lacto/Neolacto (glycan 19) signals, which were normalized with the positive control signal 3 of the same micro array collected from the 15 CSC HPs, were plotted. The maximal standard derivation for glycan 19 and 26 are $0.033 \%$ and $0.019 \%$, respectively. (D) The relative intensities of glycan 63 and glycan 69 signals from the 15 CSC HPs were plotted. The maximal standard derivation for glycan 63 and 69 are $0.012 \%$ and $0.007 \%$, respectively. (E) The IF images of stem-cellspecific glycan markers on human PANC-1, HT29, H1650, and mouse CT26 CSCs were performed with monoclonal antibodies against Globo series (SSEA-4 and GbH), Lacto series (SSEA-5), and Neolacto series (SSEA-1 and Le ${ }^{\mathrm{Y}}$ ).

between Rd-CSC HP-hP2 and BSA-Gb4 or BSA-GbH were suggested because more free forms of Rd-CSC HPhP2 were monitored.

\section{DISCUSSION}

Based on the development of the serum-free culture method to prepare CSCs, a series of CSC HPs were screened by a method composed of a negative selection with CCs and positive selection with CSCs. In random conditions, the possibility of successively picking up the same items from a library of $10^{9}$ kinds of items is $10^{-9}$. After the selection procedures, CSC HP-1 happened 10 times among the 31 valid sequences, indicating that the selection procedures were highly effective. In the other case, CSC HP-hP1 occurred 17 times among the 20 valid sequences, further confirming the efficiency of the selection strategy. In 2012, up to 744 tumor homing peptides (THPs) that had been reported or patented were collected in the TumorHoPe database [64]. Among these THPs, 36 peptides contained the RGD motif, which specifically recognized the angiogenic blood vessel markers integrin $\alpha v \beta 3$ and $\alpha v \beta 5$ $[57,58]$ and 41 peptides that contained the NGR motif. This motif binds to aminopeptidase N (CD13) [59, 60], a tumor angiogenesis marker, as well. None of the 15 CSC HPs reported in this study matched to the 744 THPs, simply because of different panning strategies. The strategies of THPs isolation were based on the differences either between cancer cells and normal cells or between tumor blood vessel and normal blood vessel. On the other hand, the strategy of CSC HPs screening was based on the differences between cancer stem cells and cancer cells. The vast cells in a tumor may be destroyed by THP-drug complex. The drug resistant CSCs can be further trapped by CSC HPs.

It is reasonable to picture that the distribution patterns of CSC surface markers on various types of CSCs are different. To confirm this postulation, the primary CSC HP-library was selected directly once by either CT26 or Hepa1-6 CSCs. As illustrated by the data shown in Table 1 , CSC HP-8 was the most attractive for CT26, and CSC
A

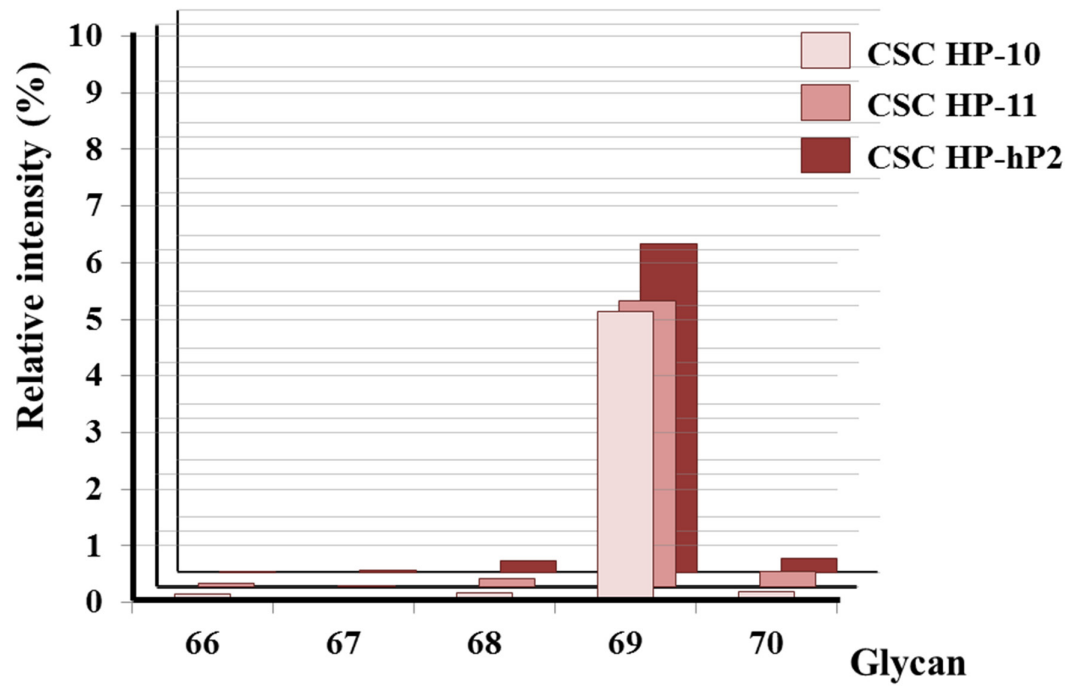

B

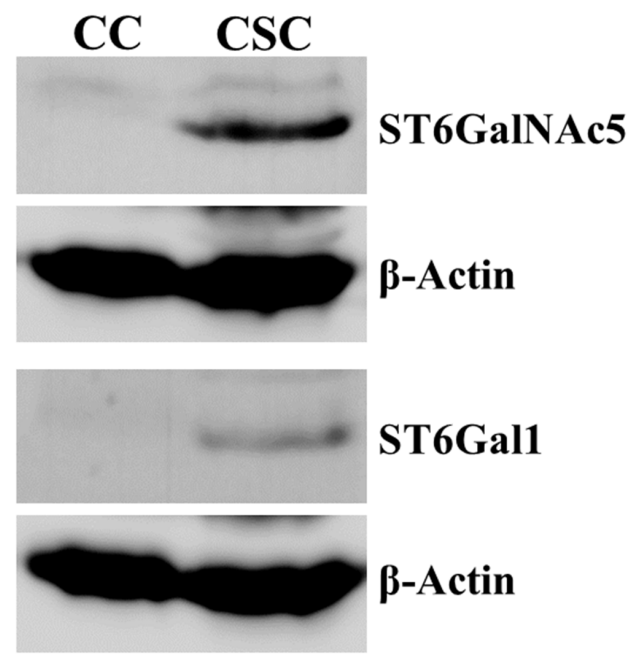

Figure 6: Analysis of $\boldsymbol{\alpha - 2 , 6 - s i a l y l a t i o n ~ o n ~ t h e ~ t e r m i n a l ~ G a l - \beta - 1 , 3 - G a l N A c - ~ g l y c a n ~ m o i e t y . ~ ( A ) ~ T h e ~ r e l a t i v e ~ i n t e n s i t i e s ~ o f ~}$ glycan 66 (Gal- $\beta-1,3-$ GalNAc- $\beta$-), glycan 67 (Gal- $\beta$-1,3-(Neu5Ac- $\alpha-2,6)-G a l N A c-\beta-)$, glycan 68 (Neu5Ac- $\alpha-2,6-G a l-\beta-1,3-G a l N A c-\beta-)$, glycan 69 (Neu5Ac- $\alpha-2,6-$ Gal- $\beta-1,3-(N e u 5 A c-\alpha-2,6)-G a l N A c-\beta-)$, and glycan 70 (Neu5Ac- $\alpha-2,3-G a l-\beta-1,3-(N e u 5 A c-\alpha-2,6)-G a l N A c-\beta-)$ signals collected from CSC HP-10, CSC HP-11, and CSC HP-hP2 chips were plotted. (B) Western blotting analysis of ST6GalNAc5 and ST6Gal1 protein expression in PANC-1 CCs and CSCs. $\beta$-actin was illustrated as internal control. 
HP-3 was exclusively selected by Hepa1-6 CSCs. The bias of CSC HP affinities between CSCs and embryonic stem cells (ESCs) was another interesting issue. The CSC HP-1 was further enriched in the ESC bound fraction (CSC/ESC-HP-library), indicating that the target of CSC HP-1 may be a general stem cell surface marker. Two new peptides, CSC HP-9 and CSC HP-12, were read in the ESC unbound fraction (CSC HP-library) only.

SSEA-1, SSEA-3, SSEA-4, SSEA-5, GbH, and Le ${ }^{\mathrm{Y}}$ pluripotent stem cell markers are the oligo-saccharide moieties of glycosphingolipids that are composed of complex glycans linked to sphingosines and various fatty acid chains [68-70]. The sphingosine and fatty acid part is also named as ceramide (Cer). According to the first hexose attached to the 1-hydroxyl of Cer via a $\beta$-glycosidic bond, mammalian glycosphingolipids can be divided into glucose- and galactose-subfamilies [71]. The galactose-subfamily (GalCer) and its 3-O-sulfated derivatives are predominant glycans in the brain. The glucose-subfamily (GlcCer) is further categorized into the Globo (Gb), Isoglobo (iGb), Lacto (Lc), Neolacto (nLc), and Ganglio (Gg) series according to the first tetrasaccharide root structures. SSEA-3 (Gb5), SSEA-4, and $\mathrm{GbH}$ are members of the Gb series. SSEA-1 and $\mathrm{Le}^{\mathrm{Y}}$ are members of the $\mathrm{nLc}$ and SSEA-5 is a member of Lc series (Supplementary Figure 2A). During the early stage of mouse embryonic development, the Gb-series member SSEA3/4 is expressed at first with maximum at 4-cell stage. Then the nLc-series member SSEA-1 is maximally expressed at 8-32 cell morula stage followed by $\mathrm{Le}^{\mathrm{Y}}$ of the same series at early blastula stage. The members of Ggseries are detected after implantation [66, 67].

According to the glycan microarray data, CSC HP-1 and CSC HP-hP1 bound strongly and specifically to glycan 26 , which is the Globo root structure of tetrasaccharides. It can be concluded that, corresponding to the library screening data, CSC HP-1 and CSC HP-hP1 bind to general stem cell surface markers. On the other hand, CSC HP-5, CSC HP-6, CSC HP-7, and CSC HP9 bound strongly to glycan 19, which is the core trisaccharide of Lacto and Neolacto root structure tetrasaccharides. The CSC HP-3 and CSC HP-8, speculated as being specific to liver and colon CSCs, respectively, were found weakly bound to glycan 26. The real targets of CSC HP-3 and CSC HP-8 remain to be identified. CSC HP-1 and CSC HP-hP1 were the two CSC HP members that bound more strongly to glycan $63, \mathrm{Le}^{\mathrm{Y}}$ epitope, while the affinities were moderate only.

In addition to the well-known glycan moieties of stem cell markers, a new oligo-saccharide, glycan 69 (Neu5Ac- $\alpha-2,6-$ Gal- $\beta-1,3-($ Neu5Ac- $\alpha-2,6)$-GalNAc- $\beta$-), was found to be strongly associated with the CSC HP9, CSC HP-10, CSC HP-11, CSC HP-hP2, and CSC $\mathrm{HP}-\mathrm{hP} 3$. Corresponding to the results that the two Neu5Ac- $\alpha-2,6-$ residues were necessary for these CSC HPs binding (Figure 5E), the enzymes possibly catalyzing the sialylation reactions, ST6Gal1 [72] and ST6GalNAc5 [73], were found to be highly expressed in malignant and

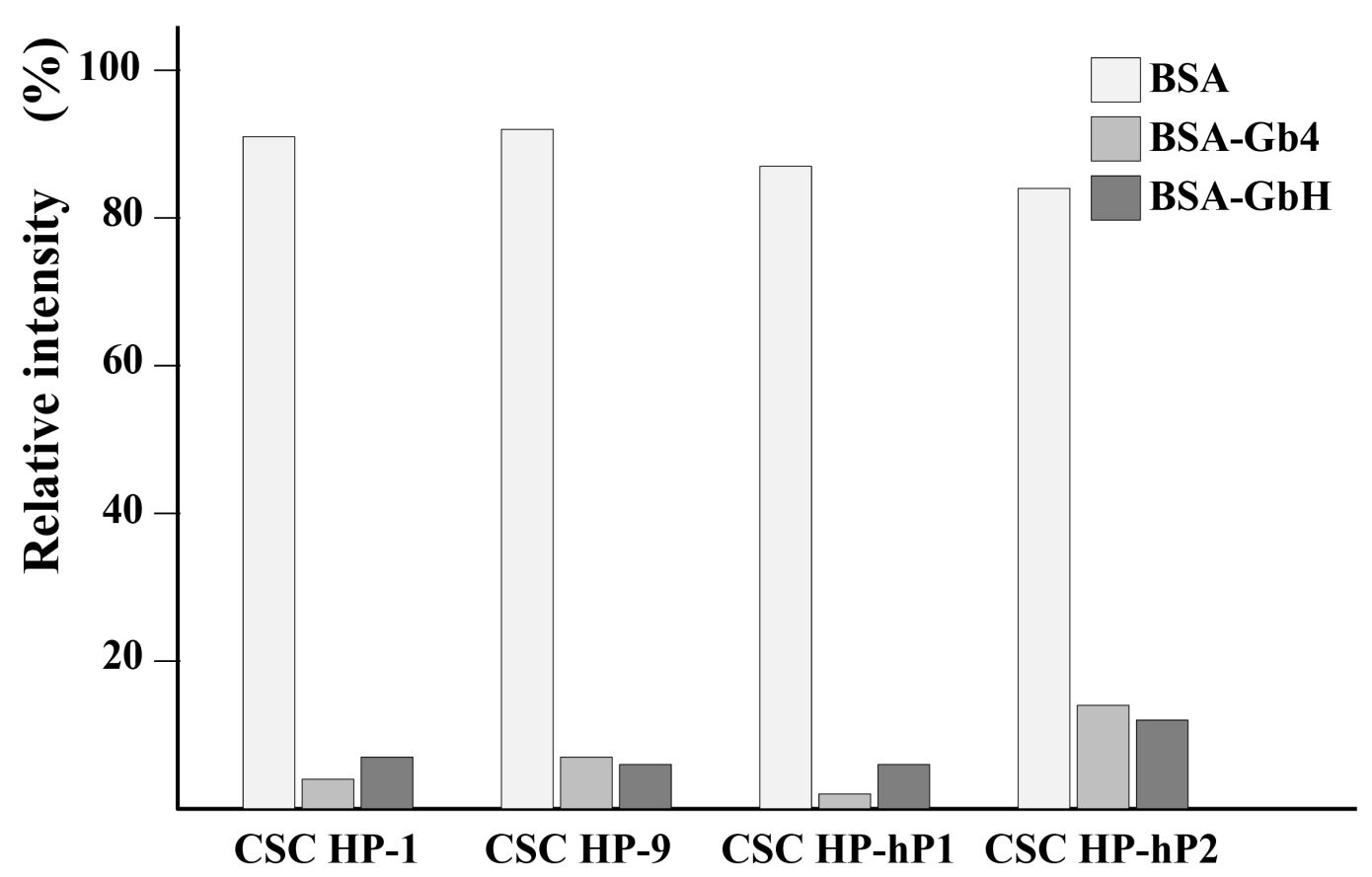

Figure 7: Binding assay of CSC HPs on Gb glycans conjugated on BSA. The rodomine labeled CSC HPs, Rd-CSC HP-1, RdCSC HP-9, Rd-CSC HP-hP1, and Rd-CSC HP-hP2, were mixed with equimolar of BSA, Gb4-BSA or GbH-BSA. The free form of these Rd-CSC HPs were separated from which associated with BSA or Gb-BSA by ultra-filtration. In the absence of BSA or Gb-BSA, the relative fluorescence intensity of these Rd-CSC HPs in the filtrate were defined as $100 \%$. 
metastatic tumors and corresponding to a worse prognosis [74-76]. Our western blotting data illustrated that both ST6Gal1 and ST6GalNAc5 were expressed in PANC-1 CSCs but not in PANC-1 CC (Figure 6B). Further studies are still needed to determine whether glycan 69 can be considered as a novel CSC marker.

In addition to the PANC-1 CSCs that could be bound by CSC HP-hP1-DsRed recombinant protein, a minority of the CCs were also stained by the recombinant protein (Figure 4B). This result indicates that PANC-1 cells cultured in serum-containing medium were heterogeneous as suggested by the stem cell model of cancer [77, 78]. These CSCs could be selectively amplified in the defined serum-free medium in suspension state. The CSCs in the tumorospheres, even expressing much higher levels of stem cell markers, should be heterogeneous as well. The linkage of the fluorescent dye to the N-terminus or the DsRed protein to the C-terminus of CSC HP-hP1 did not block its interactions with CSCs. These results indicate that the CSC HPs are potential vehicles to deliver antiCSC reagents, either large or small molecules.

\section{MATERIALS AND METHODS}

\section{Cancer cell and cancer stem cell cultures}

Recombinant growth factors were purchased from PeproTech. Culture media and nutrient supplements were obtained from Invitrogen. Chemicals were acquired from Sigma-Aldrich. Mouse breast cancer EMT6, liver cancer Hepa1-6 and human pancreatic ductal adenoma PANC1 cell lines were maintained in DMEM supplemented with 10\% FCS. Mouse colon cancer CT26 and human lung cancer cell line H1650 were cultured in RPMI1640 supplemented with $10 \%$ FCS. Human colon cancer cell line HT29 was maintained in McCoy's 5A complete medium supplemented with $10 \%$ FCS. The basic culture medium for CSCs was DMEM/F12 with $2 \mathrm{mM}$ glutamine and the supplements for EMT6 CSCs were $25 \mathrm{ng} / \mathrm{mL}$ $\mathrm{rmEGF}, 25 \mathrm{ng} / \mathrm{mL} \mathrm{rmFGF} 2,5 \mu \mathrm{g} / \mathrm{mL}$ insulin, $4 \mu \mathrm{g} / \mathrm{mL}$ heparin, $0.5 \mu \mathrm{g} / \mathrm{mL}$ hydrocortisone, and $1 \% \mathrm{BSA}$; for CT26 they were $20 \mathrm{ng} / \mathrm{mL} \mathrm{rmEGF}, 5 \mu \mathrm{g} / \mathrm{mL}$ insulin, $2 \% \mathrm{~B} 27$, and $0.4 \% \mathrm{BSA}$; for Hepa1-6 that were $20 \mathrm{ng} /$ $\mathrm{mL} \mathrm{rmEGF}, 10 \mathrm{ng} / \mathrm{mL} \mathrm{rmFGF} 2,2 \% \mathrm{~B} 27$, and $1 \% \mathrm{~N} 2$; for PANC-1 they were $2 \% \mathrm{~B} 27$ and $20 \mathrm{ng} / \mathrm{mL} \mathrm{rhFGF} 2$; for HT29 they were $20 \mathrm{ng} / \mathrm{mL}$ rhEGF, $5 \mu \mathrm{g} / \mathrm{mL}$ insulin, $2 \%$ B27, and $0.4 \% \mathrm{BSA}$; and for $\mathrm{H} 1650$ they were $20 \mathrm{ng} / \mathrm{mL}$ rhEGF, $10 \mathrm{ng} / \mathrm{mL}$ rhFGF2, 1\% ITS, $10 \mu \mathrm{g} / \mathrm{mL}$ putrescine, $2 \mu \mathrm{M}$ progesterone, and $0.4 \% \mathrm{BSA}$. In order to prepare tumorospheres, cancer cells were cultured in the serumfree media at low density, $<10^{4} / \mathrm{mL}$. After 7 days of incubation, the tumorospheres were harvested using a $40 \mu \mathrm{m}$ cell strainer, and they were centrifuged for $5 \mathrm{~min}$ at $900 \times \mathrm{g}$ at RT. The pellets of the tumorospheres were dissociated to single cells by trypsin, and then the obtained cells were expanded into tumorospheres again for another
7 days. Growth factors were replenished every second day, and tumorospheres isolated in the third to fifth round of expansion were used for experiments.

\section{M13 phage display}

The M13 PhD-7 library (NEB, E8100) which contains $1 \times 10^{9}$ independent clones was purchased from New England Biolabs Inc. $1 \times 10^{13}$ plaque firming units (pfus) of M13 PhD-7 phages in $10 \mathrm{~mL}$ DMEM were pre-adsorbed by cancer cells in a T75 flask twice, each for 1 hour. Then the supernatant was transferred to a T25 flask containing $5 \times 10^{6}$ CSCs and incubated for 1 hour. The unbound and weakly associated phages were removed by centrifugation and suspension three times in DMEM/0/2\% BSA. The cell pellet was suspended in 1 $\mathrm{mL}$ PBS containing $1 \times 10^{9} \mathrm{E}$. coli $\mathrm{ER} 2738$ and incubated in a shaker for 1 hour. Then, $10 \mathrm{~mL} \mathrm{LB} / 5 \mathrm{mM} \mathrm{MgCl}_{2}$ was added. After being cultured over-night at $37^{\circ} \mathrm{C}$, the cells were removed by centrifugation and phages in the supernatant were titrated. The aforementioned selection procedures were carried out for three rounds for EMT6 (Figure 2A) and PANC-1 (Figure 2B) to obtain the primary EMT6 CSC HP- and PANC-1 CSC HP-library, respectively. Then, M13 plaques were picked up to prepare the DNA for sequencing. The EMT6 CSC HPlibrary was further selected by CT26 CSCs, Hepa1-6 CSCs, and mouse embryonic stem cells ESC (mESCs) again to prepare the secondary CT26 CSC HP-, Hepa1-6 CSC HP-, and CSC/ES HP-library. The unbound fraction after $\mathrm{mESC}$ adsorption was collected and as signed as the CSC PH-library (Figure 2A).

\section{Glycan microarray analysis}

The N-terminus biotin conjugated CSC HPs were synthesized by GeneDirex Inc. with purity higher than $98 \%$ and were listed in Table 2. Glycan Array 100 microchips (Cat. \# GA-Glycan-100) were purchased from RayBiotech and were processed following the manufacturer's instruction with some modifications. Briefly, after blocking with $400 \mu \mathrm{L}$ Sample Diluent (Item E) at room temperature for $30 \mathrm{~min}$, the biotin conjugated CSC HPs were diluted to $1 \mu \mathrm{g} / 400 \mu \mathrm{L}$ with Sample Diluent, and hybridization reactions were carried out at room temperature for 2 hours. After washing, $400 \mu \mathrm{L}$ of $1 \times$ Cy3-conjugated streptavidin was added to each well. The incubation chamber was covered with the plastic adhesive strips and cover the slide with aluminum foil to avoid exposure to light during incubating in a dark room. The slide was incubated with Cy3-conjugated streptavidin at RT for 1 hour with gentle rocking or shaking. After thorough washing, the slide was drained completely, and the fluorescent signals on it were read by laser scanner Axon GenePix. The relative intensity on glycan $\mathrm{X}$ was defined as (average of $\mathrm{X}$ - negative control)/(positive control - negative control) $\times 100 \%$. 


\section{IF assay}

The primary antibodies, rabbit polyclonal antibodies against CD44 (GTX102111), E-cadherin (GTX61823) and CDSN (GTX110093) as well as mouse monoclonal antibodies against SSEA-1 (GTX48038), SSEA-5 (GTX70019), and Lewis Y (GTX75903), were purchased from GeneTex; mouse monoclonal antibodies against SSEA-4 (SCR001 Part No. 90231), TRA-1-60 (SCR001 Part No. 90232) and TRA-1-81 (SCR001 Part No. 90233) were from Merck-Millipore; mouse monoclonal antibody against GbH (IgM, ALX-804-550) was from Enzo. The secondary antibodies DyLight594-conjugated goat antirabbit IgG (111-515-144) and DyLight488-conjugated donkey anti-mouse IgG (715-485-151) were obtained from Jackson Lab.; DyLight594-conjugated goat antimouse IgM (GTX76754) was obtained from GeneTex. The antibodies used in this report were summarized in Supplementary Table 1. Cancer cells and tumorospheres were fixed by $4 \%$ paraformaldehyde/PBS. Then the cells were incubated with primary antibodies that were diluted in TBS/1\%BSA (25 mM Tris- $\mathrm{HCl}, \mathrm{pH} 7.4 / 150 \mathrm{mM}$ $\mathrm{NaCl} / 1 \% \mathrm{BSA}$ ) by 50 to 100 fold for two hours. After 4 times washes with TBS ( $25 \mathrm{mM}$ Tris- $\mathrm{HCl}, \mathrm{pH} 7.4 / 150 \mathrm{mM}$ $\mathrm{NaCl}$ ), the cells were incubated with secondary antibodies (1/200 dilution in TBS/1\%BSA) for 2 hours. After 4 washes with TBS and one brief wash with water, the cells were mounted with ProLong ${ }^{\circledR}$ Gold Antifade Mount with DAPI (Invitrogen, P36935).

\section{Western blotting assay}

The primary antibodies, rabbit polyclonal antibodies against ST6GalNAc5 (GTX45949), ST6Gal1 (GTX104018) and $\beta$-actin (GTX109369), and secondary HRP-conjugated goat anti-rabbit antibody were purchased from GeneTex. Each $100 \mu \mathrm{g}$ of total lysate proteins from PANC-1 CCs or CSCs were separated by SDS PAGE before transferred onto a PVDF membrane. The primary antibodies against ST6GalNAc5, ST6Gal1 and $\beta$-actin were diluted by 1000,1000 and 5000 folds, respectively, in blocking solution $(20 \mathrm{mM}$ Tris- $\mathrm{HCl}, \mathrm{pH} 7.5 / 150 \mathrm{mM}$ $\mathrm{NaCl} / 3 \%$ non-fat milk). After incubation with the primary antibodies for 2 hours, the membranes were washed with wash solution $(20 \mathrm{mM}$ Tris-HCl, $\mathrm{pH} 7.5 / 150 \mathrm{mM}$ $\mathrm{NaCl} / 0.05 \%$ Tween-20) for 4 times. Then the membranes were incubated with the secondary antibody which was diluted in blocking solution for 2500 folds for 2 hours and washed for 4 times. ECL HRP substrate (Thermo-Fisher, 34075) was used to perform the chemiluminescent signals and images were taken with a CCD imaging system.

\section{Recombinant protein preparation}

Supplementary Figure 1 shows the map of pET-CSC HP-hP1-DsRed vector. The E.coli Rosetta gamiB(DE3) pLysS host cells transformed by pET-CSC HP-hP1-DsRed were grown in $2 \times \mathrm{YT}$ supplemented with $0.4 \%$ glucose, $30 \mu \mathrm{g} / \mathrm{mL}$ chloramphenicol, and $50 \mu \mathrm{g} / \mathrm{mL}$ ampicillin at $37^{\circ} \mathrm{C}$. IPTG was adjusted to $1 \mathrm{mM}$ when $\mathrm{OD}_{600}$ was 0.6 and cells were cultured for another $4 \mathrm{~h}$. Then cells were collected by centrifugation at $10,000 \mathrm{~g}$ for $10 \mathrm{~min}$. After ultra-sonication, the soluble form of CSC HP-hP1DsRed recombinant protein was purified by using the $\mathrm{Ni}$ Sepharose 6 Fast Flow (17-5318-02, GE) affinity column following the manufacturer's instructions.

\section{Association between CSC HPs and CSCs}

The N-terminus rhodamine- or fluoresceinconjugated CSC HPs were synthesized by GeneDirex Inc. with purity higher than $98 \%$ and were listed in Table 2. Cancer cells and tumorospheres fixed by $4 \%$ paraformaldehyde/PBS were incubated with $50 \mu \mathrm{g} / \mathrm{mL}$ of the conjugated peptides in TBS/1\%BSA for an hour. After 3 times washes with TBS and a brief wash with water, the cells were mounted with ProLong ${ }^{\circledR}$ Gold Antifade Mount with DAPI (Invitrogen, P36935).

\section{Association between CSC HPs and oligo-saccharides}

Gb4-conjugated BSA (GLY121-BSA) and GbHconjugated BSA (GLY123-BSA) were purchased from ELICITYL. The final concentrations of Rd-conjugated CSC HP-1, CSC HP-9, CSC HP-hP1, or CSC HP-hP2 were adjusted to $10 \mu \mathrm{g} / \mathrm{mL}$ and of BSA, Gb4-BSA or GbHBSA were adjusted to $700 \mu \mathrm{g} / \mathrm{mL}$ in TNTD (10 mM Tris$\mathrm{HCl}, \mathrm{pH} 7.4 / 50 \mathrm{mM} \mathrm{NaCl} / 0.02 \%$ Tween $20 / 0.02 \%$ sodium deoxycholate). After incubation for 30 minutes, the free Rd-CSC HPs were separated from those associated with BSA, Gb4-BSA or GbH-BSA by ultra-filtration. Amicon Ultra-0.5 tubes (Merck-Millipore, UFC501024, $10 \mathrm{kDa}$ cutoff) were pre-run with $0.5 \mathrm{~mL}$ of blocking solution (10 mM Tris- $\mathrm{HCl}, \mathrm{pH} 7.4 / 50 \mathrm{mM} \mathrm{NaCl} / 0.2 \%$ Tween $20 / 0.2 \%$ sodium deoxycholate) to prevent non-specific adhesions of Rd-CSC HPs onto the filter. Each $0.25 \mathrm{~mL}$ of Rd-CSC HPs/Gb-BSA mixtures were loaded to the inner tubes. Centrifugation was set at $5000 \mathrm{rpm}$. The volume of filtrate was checked every 5 minutes. When about half of the samples were filtrated, each $100 \mu \mathrm{L}$ of the filtrate was transferred to a well of a black 96-well plate. The fluorescent data were detected with a reader, FLUOstar Omega (BMG LABTECH), by setting the excitation wave length at $544 \mathrm{~nm}$ and emission wave length at $620 \mathrm{~nm}$.

\section{Abbreviations}

ABC: ATP-binding cassette; CC: cancer cell; CSC: cancer stem cell; EMT: epithelialmesenchymal transition; MTS: multicellular tumor spheroids; SCID: severe combined immune-deficient; SSEA: stage-specific embryonic antigen; ST6Gal1: 
$\beta$-galactoside $\alpha$-2,6-sialyltransferase 1; ST6GalNAc5: $\mathrm{N}$-acetylgalactosaminide $\alpha$-2,6-sialyltransferase 5; THP: tumor homing peptide; TIC: tumor initiating cell.

\section{Author contributions}

YSS and TYL operated experiments and did data analysis. HJL and CKC designed and supervised this project.

\section{ACKNOWLEDGMENTS}

We want to thanks Miss Hsin-Hui Hsieh at Tseng Hsiang Life Science Ltd. for her technical assistances for the image performance and capture of the glycan microarrays.

\section{CONFLICTS OF INTEREST}

The authors declare no conflicts of interest.

\section{FUNDING}

This work was supported by the grants NSC 102-2320-B-059-001-MY3, MOST 104-2321-B-866002, MOST 105-2321-B-866-001 and MOST 106-2321B-866-001 from the ministry of science and technology and 106AS-6.2.1-ST-al from the council of agriculture, executive yuan, Taiwan.

\section{REFERENCES}

1. Lapidot T, Sirard C, Vormoor J, Murdoch B, Hoang T, Caceres-Cortes J, Minden M, Paterson B, Caligiuri MA, Dick JE. A cell initiating human acute myeloid leukaemia after transplantation into SCID mice. Nature. 1994; 367:645-648.

2. Al-Hajj M, Wicha MS, Benito-Hernandez A, Morrison SJ, Clarke MF. Prospective identification of tumorigenic breast cancer cells. Proc Natl Acad Sci U S A. 2003; 100:3983-3988.

3. Singh SK, Clarke ID, Terasaki M, Bonn VE, Hawkins C, Squire J, Dirks PB. Identification of a cancer stem cell in human brain tumors. Cancer Res. 2003; 63:5821-5828.

4. Suetsugu A, Nagaki M, Aoki H, Motohashi T, Kunisada T, Moriwaki H. Characterization of CD133+ hepatocellular carcinoma cells as cancer stem/progenitor cells. Biochem Biophys Res Commun. 2006; 351:820-824.

5. O'Brien CA, Pollett A, Gallinger S, Dick JE. A human colon cancer cell capable of initiating tumour growth in immunodeficient mice. Nature. 2007; 445:106-110.

6. Ma S, Chan KW, Hu L, Lee TK, Wo JY, Ng IO, Zheng BJ, Guan XY. Identification and characterization of tumorigenic liver cancer stem/progenitor cells. Gastroenterology. 2007; 132:2542-2556.

7. Wang YH, Li F, Luo B, Wang XH, Sun HC, Liu S, Cui YQ, $\mathrm{Xu} \mathrm{XX}$. A side population of cells from a human pancreatic carcinoma cell line harbors cancer stem cell characteristics. Neoplasma. 2009; 56:371-378.

8. Srinivasan T, Walters J, Bu P, Than EB, Tung KL, Chen KY, Panarelli N, Milsom J, Augenlicht L, Lipkin SM, Shen X. NOTCH Signaling Regulates Asymmetric Cell Fate of Fastand Slow-Cycling Colon Cancer-Initiating Cells. Cancer Res. 2016; 76:3411-3421.

9. van Niekerk G, Davids LM, Hattingh SM, Engelbrecht AM. Cancer stem cells: A product of clonal evolution? Int J Cancer. 2017; 140:993-999.

10. Abbaszadegan MR, Bagheri V, Razavi MS, Momtazi AA, Sahebkar A, Gholamin M. Isolation, identification, and characterization of cancer stem cells: A review. J Cell Physiol. 2017; 232:2008-18.

11. Chen J, Li Y, Yu TS, McKay RM, Burns DK, Kernie SG, Parada LF. A restricted cell population propagates glioblastoma growth after chemotherapy. Nature. 2012; 488:522-526.

12. Rycaj K, Tang DG. Cancer stem cells and radioresistance. Int J Radiat Biol. 2014; 90:615-621.

13. Tanei T, Morimoto K, Shimazu K, Kim SJ, Tanji Y, Taguchi T, Tamaki Y, Noguchi S. Association of breast cancer stem cells identified by aldehyde dehydrogenase 1 expression with resistance to sequential Paclitaxel and epirubicin-based chemotherapy for breast cancers. Clin Cancer Res. 2009; 15:4234-4241.

14. Stacy AE, Jansson PJ, Richardson DR. Molecular pharmacology of ABCG2 and its role in chemoresistance. Mol Pharmacol. 2013; 84:655-669.

15. Grimm M, Krimmel M, Polligkeit J, Alexander D, Munz A, Kluba S, Keutel C, Hoffmann J, Reinert S, Hoefert $\mathrm{S}$. ABCB5 expression and cancer stem cell hypothesis in oral squamous cell carcinoma. Eur J Cancer. 2012; 48:3186-3197.

16. Colak S, Medema JP. Cancer stem cells--important players in tumor therapy resistance. FEBS J. 2014; 281:4779-4791.

17. Bruttel VS, Wischhusen J. Cancer stem cell immunology: key to understanding tumorigenesis and tumor immune escape? Front Immunol. 2014; 5:360.

18. Maccalli C, De Maria R. Cancer stem cells: perspectives for therapeutic targeting. Cancer Immunol Immunother. 2015; 64:91-97.

19. Maiso P, Huynh D, Moschetta M, Sacco A, Aljawai Y, Mishima Y, Asara JM, Roccaro AM, Kimmelman AC, Ghobrial IM. Metabolic signature identifies novel targets for drug resistance in multiple myeloma. Cancer Res. 2015; 75:2071-2082.

20. Wong TL, Che N, Ma S. Reprogramming of central carbon metabolism in cancer stem cells. Biochim Biophys Acta. 2017; 1863:1728-1738. 
21. De Miguel MP, Alcaina Y, de la Maza DS, Lopez-Iglesias P. Cell metabolism under microenvironmental low oxygen tension levels in stemness, proliferation and pluripotency. Curr Mol Med. 2015; 15:343-359.

22. Dragu DL, Necula LG, Bleotu C, Diaconu CC, ChivuEconomescu M. Therapies targeting cancer stem cells: Current trends and future challenges. World J Stem Cells. 2015; 7:1185-1201.

23. Talukdar S, Emdad L, Das SK, Sarkar D, Fisher PB. Evolving Strategies for Therapeutically Targeting Cancer Stem Cells. Adv Cancer Res. 2016; 131:159-191.

24. Carrasco E, Alvarez PJ, Prados J, Melguizo C, Rama AR, Aránega A, Rodríguez-Serrano F. Cancer stem cells and their implication in breast cancer. Eur J Clin Invest. 2014; 44:678-687.

25. Botchkina G. Colon cancer stem cells--from basic to clinical application. Cancer Lett. 2013; 338:127-140.

26. Kozovska Z, Gabrisova V, Kucerova L. Colon cancer: cancer stem cells markers, drug resistance and treatment. Biomed Pharmacother. 2014; 68:911-916.

27. Qureshi-Baig K, Ullmann P, Rodriguez F, Frasquilho S, Nazarov PV, Haan S, Letellier E. What Do We Learn from Spheroid Culture Systems? Insights from Tumorspheres Derived from Primary Colon Cancer Tissue. PLoS One. 2016; 11:e0146052.

28. Chen Y, Yu D, Zhang H, He H, Zhang C, Zhao W, Shao RG. CD133(+)EpCAM(+) phenotype possesses more characteristics of tumor initiating cells in hepatocellular carcinoma Huh7 cells. Int J Biol Sci. 2012; 8:992-1004.

29. Sun JH, Luo Q, Liu LL, Song GB. Liver cancer stem cell markers: Progression and therapeutic implications. World J Gastroenterol. 2016; 22:3547-3557.

30. Zhan HX, Xu JW, Wu D, Zhang TP, Hu SY. Pancreatic cancer stem cells: new insight into a stubborn disease. Cancer Lett. 2015; 357:429-437.

31. Ercan G, Karlitepe A, Ozpolat B. Pancreatic Cancer Stem Cells and Therapeutic Approaches. Anticancer Res. 2017; 37:2761-2775.

32. Yamada T, Abei M, Danjoh I, Shirota R, Yamashita T, Hyodo I, Nakamura Y. Identification of a unique hepatocellular carcinoma line, Li-7, with CD13(+) cancer stem cells hierarchy and population change upon its differentiation during culture and effects of sorafenib. BMC Cancer. 2015; 15:260.

33. Mani SA, Guo W, Liao MJ, Eaton EN, Ayyanan A, Zhou AY, Brooks M, Reinhard F, Zhang CC, Shipitsin M, Campbell LL, Polyak K, Brisken C, et al. The epithelialmesenchymal transition generates cells with properties of stem cells. Cell. 2008; 133:704-715.

34. Fan F, Samuel S, Evans KW, Lu J, Xia L, Zhou Y, Sceusi E, Tozzi F, Ye XC, Mani SA, Ellis LM. Overexpression of snail induces epithelial-mesenchymal transition and a cancer stem cell-like phenotype in human colorectal cancer cells. Cancer Med. 2012; 1:5-16.
35. Dontu G, Abdallah WM, Foley JM, Jackson KW, Clarke $\mathrm{MF}$, Kawamura MJ, Wicha MS. In vitro propagation and transcriptional profiling of human mammary stem/ progenitor cells. Genes Dev. 2003; 17:1253-1270.

36. Gilmore AP. Anoikis. Cell Death Differ. 2005; 12:1473-1477.

37. Walker S, Foster F, Wood A, Owens T, Brennan K, Streuli $\mathrm{CH}$, Gilmore AP. Oncogenic activation of FAK drives apoptosis suppression in a 3D-culture model of breast cancer initiation. Oncotarget. 2016; 7:70336-52. https://doi. org/10.18632/oncotarget.11856.

38. Grimshaw MJ, Cooper L, Papazisis K, Coleman JA, Bohnenkamp HR, Chiapero-Stanke L, Taylor-Papadimitriou J, Burchell JM. Mammosphere culture of metastatic breast cancer cells enriches for tumorigenic breast cancer cells. Breast Cancer Res. 2008; 10:R52.

39. Manuel Iglesias J, Beloqui I, Garcia-Garcia F, Leis O, Vazquez-Martin A, Eguiara A, Cufi S, Pavon A, Menendez JA, Dopazo J, Martin AG. Mammosphere formation in breast carcinoma cell lines depends upon expression of E-cadherin. PLoS One. 2013; 8:e77281.

40. Fang D, Nguyen TK, Leishear K, Finko R, Kulp AN, Hotz S, Van Belle PA, Xu X, Elder DE, Herlyn M. A tumorigenic subpopulation with stem cell properties in melanomas. Cancer Res. 2005; 65:9328-9337.

41. Singh SK, Hawkins C, Clarke ID, Squire JA, Bayani J, Hide T, Henkelman RM, Cusimano MD, Dirks PB. Identification of human brain tumour initiating cells. Nature. 2004; 432:396-401.

42. Ricci-Vitiani L, Lombardi DG, Pilozzi E, Biffoni M, Todaro M, Peschle C, De Maria R. Identification and expansion of human colon-cancer-initiating cells. Nature. 2007; 445:111-115.

43. Hermann PC, Huber SL, Herrler T, Aicher A, Ellwart JW, Guba M, Bruns CJ, Heeschen C. Distinct populations of cancer stem cells determine tumor growth and metastatic activity in human pancreatic cancer. Cell Stem Cell. 2007; 1:313-323.

44. Weiswald LB, Bellet D, Dangles-Marie V. Spherical cancer models in tumor biology. Neoplasia. 2015; 17:1-15. https:// doi.org/10.1016/j.neo.2014.12.004.

45. Weiswald LB, Guinebretière JM, Richon S, Bellet D, Saubaméa B, Dangles-Marie V. In situ protein expression in tumour spheres: development of an immunostaining protocol for confocal microscopy. BMC Cancer. 2010; 10:106.

46. Kojima N, Takeuchi S, Sakai Y. Establishment of selforganization system in rapidly formed multicellular heterospheroids. Biomaterials. 2011; 32:6059-6067.

47. Urbanelli L, Ronchini C, Fontana L, Menard S, Orlandi R, Monaci P. Targeted gene transduction of mammalian cells expressing the HER2/neu receptor by filamentous phage. J Mol Biol. 2001; 313:965-976. 
48. Ding H, Prodinger WM, Kopecek J. Identification of CD21binding peptides with phage display and investigation of binding properties of HPMA copolymer-peptide conjugates. Bioconjug Chem. 2006; 17:514-523.

49. Spear MA, Breakefield XO, Beltzer J, Schuback D, Weissleder R, Pardo FS, Ladner R. Isolation, characterization, and recovery of small peptide phage display epitopes selected against viable malignant glioma cells. Cancer Gene Ther. 2001; 8:506-511.

50. Jiang YQ, Wang HR, Li HP, Hao HJ, Zheng YL, Gu J. Targeting of hepatoma cell and suppression of tumor growth by a novel 12 mer peptide fused to superantigen TSST-1. Mol Med. 2006; 12:81-87.

51. Lee TY, Wu HC, Tseng YL, Lin CT. A novel peptide specifically binding to nasopharyngeal carcinoma for targeted drug delivery. Cancer Res. 2004; 64:8002-08.

52. Chang DK, Lin $\mathrm{CT}, \mathrm{Wu} \mathrm{CH}, \mathrm{Wu} \mathrm{HC}$. A novel peptide enhances therapeutic efficacy of liposomal anti-cancer drugs in mice models of human lung cancer. PLoS One. 2009; 4:e4171.

53. McGuire MJ, Gray BP, Li S, Cupka D, Byers LA, Wu L, Rezaie S, Liu YH, Pattisapu N, Issac J, Oyama T, Diao L, Heymach JV, et al. Identification and characterization of a suite of tumor targeting peptides for non-small cell lung cancer. Sci Rep. 2014; 4:4480.

54. Chi YH, Hsiao JK, Lin MH, Chang C, Lan CH, Wu HC. Lung Cancer-Targeting Peptides with Multi-subtype Indication for Combinational Drug Delivery and Molecular Imaging. Theranostics. 2017; 7:1612-1632.

55. Forster JC, Harriss-Phillips WM, Douglass MJ, Bezak E. A review of the development of tumor vasculature and its effects on the tumor microenvironment. Hypoxia (Auckl). 2017; 5:21-32.

56. Ruoslahti E. Specialization of tumour vasculature. Nat Rev Cancer. 2002; 2:83-90

57. Dechantsreiter MA, Planker E, Mathä B, Lohof E, Hölzemann G, Jonczyk A, Goodman SL, Kessler H. N-Methylated cyclic RGD peptides as highly active and selective alpha(V)beta(3) integrin antagonists. J Med Chem. 1999; 42:3033-3040.

58. Belvisi L, Riccioni T, Marcellini M, Vesci L, Chiarucci I, Efrati D, Potenza D, Scolastico C, Manzoni L, Lombardo K, Stasi MA, Orlandi A, Ciucci A, et al. Biological and molecular properties of a new alpha(v)beta3/alpha(v)beta5 integrin antagonist. Mol Cancer Ther. 2005; 4:1670-1680.

59. Curnis F, Sacchi A, Borgna L, Magni F, Gasparri A, Corti A. Enhancement of tumor necrosis factor alpha antitumor immunotherapeutic properties by targeted delivery to aminopeptidase N (CD13). Nat Biotechnol. 2000; 18:1185-1190.

60. Soudy R, Ahmed S, Kaur K. NGR peptide ligands for targeting CD13/APN identified through peptide array screening resemble fibronectin sequences. ACS Comb Sci. 2012; 14:590-599.
61. Laakkonen P, Porkka K, Hoffman JA, Ruoslahti E. A tumor-homing peptide with a targeting specificity related to lymphatic vessels. Nat Med. 2002; 8:751-755.

62. Laakkonen P, Zhang L, Ruoslahti E. Peptide targeting of tumor lymph vessels. Ann N Y Acad Sci. 2008; 1131:37-43.

63. Zhang L, Giraudo E, Hoffman JA, Hanahan D, Ruoslahti E. Lymphatic zip codes in premalignant lesions and tumors. Cancer Res. 2006; 66:5696-5706.

64. Kapoor P, Singh H, Gautam A, Chaudhary K, Kumar R, Raghava GP. TumorHoPe: a database of tumor homing peptides. PLoS One. 2012; 7:e35187.

65. Cheung SK, Chuang PK, Huang HW, Hwang-Verslues WW, Cho CH, Yang WB, Shen CN, Hsiao M, Hsu TL, Chang CF, Wong $\mathrm{CH}$. Stage-specific embryonic antigen-3 (SSEA-3) and $\beta 3$ GalT5 are cancer specific and significant markers for breast cancer stem cells. Proc Natl Acad Sci U S A. 2016; 113:960-965.

66. Hakomori SI. Structure and function of glycosphingolipids and sphingolipids: recollections and future trends. Biochim Biophys Acta. 2008; 1780:325-346.

67. Handa K, Hakomori SI. Changes of glycoconjugate expression profiles during early development. Glycoconj J. 2017; 34:693-99.

68. Ojima T, Shibata E, Saito S, Toyoda M, Nakajima H, Yamazaki-Inoue M, Miyagawa Y, Kiyokawa N, Fujimoto J, Sato T, Umezawa A. Glycolipid dynamics in generation and differentiation of induced pluripotent stem cells. Sci Rep. 2015; 5:14988.

69. Ho MY, Yu AL, Yu J. Glycosphingolipid dynamics in human embryonic stem cell and cancer: their characterization and biomedical implications. Glycoconj J. 2017; 34:765-77.

70. Yu AL, Hung JT, Ho MY, Yu J. Alterations of Glycosphingolipids in Embryonic Stem Cell Differentiation and Development of Glycan-Targeting Cancer Immunotherapy. Stem Cells Dev. 2016; 25:1532-48.

71. Merrill AH Jr. Sphingolipid and glycosphingolipid metabolic pathways in the era of sphingolipidomics. Chem Rev. 2011; 111:6387-6422.

72. Takashima S, Tsuji S, Tsujimoto M. Comparison of the enzymatic properties of mouse beta-galactoside alpha2,6sialyltransferases, ST6Gal I and II. J Biochem. 2003; 134:287-296.

73. Tsuchida A, Okajima T, Furukawa K, Ando T, Ishida H, Yoshida A, Nakamura Y, Kannagi R, Kiso M, Furukawa K. Synthesis of disialyl Lewis a (Le(a)) structure in colon cancer cell lines by a sialyltransferase, ST6GalNAc VI, responsible for the synthesis of alpha-series gangliosides. J Biol Chem. 2003; 278:22787-22794.

74. Schultz MJ, Holdbrooks AT, Chakraborty A, Grizzle WE, Landen CN, Buchsbaum DJ, Conner MG, Arend RC, Yoon KJ, Klug CA, Bullard DC, Kesterson RA, Oliver $\mathrm{PG}$, et al. The Tumor-Associated Glycosyltransferase ST6Gal-I Regulates Stem Cell Transcription Factors and Confers a Cancer Stem Cell Phenotype. Cancer Res. 2016; 76:3978-3988. 
75. Bos PD, Zhang XH, Nadal C, Shu W, Gomis RR, Nguyen DX, Minn AJ, van de Vijver MJ, Gerald WL, Foekens JA, Massagué J. Genes that mediate breast cancer metastasis to the brain. Nature. 2009; 459:1005-1009.

76. Vandermeersch S, Vanbeselaere J, Delannoy CP, Drolez A, Mysiorek C, Guérardel Y, Delannoy P, Julien S. Accumulation of GD1 $\alpha$ Ganglioside in MDA-MB-231
Breast Cancer Cells Expressing ST6GalNAc V. Molecules. 2015; 20:6913-6924.

77. Meacham CE, Morrison SJ. Tumour heterogeneity and cancer cell plasticity. Nature. 2013; 501:328-337.

78. Wang A, Chen L, Li C, Zhu Y. Heterogeneity in cancer stem cells. Cancer Lett. 2015; 357:63-68. 